\title{
SARS-CoV-2 infection in patients with serious mental illness and possible benefits of prophylaxis with Memantine and Amantadine
}

\author{
Ileana MarinesCu ${ }^{1)}$, Dragoş MarinesCu2), Laurentiu Mogoantă ${ }^{3)}$, IOn Cristian Efrem ${ }^{4}$, \\ PUIU OLIVIAN STOVICEK ${ }^{5)}$
}

\author{
${ }^{1)}$ Discipline of Psychiatry, $5^{\text {th }}$ Department, Faculty of Medicine, University of Medicine and Pharmacy of Craiova, Romania \\ ${ }^{2)}$ Doctoral School, University of Medicine and Pharmacy of Craiova, Romania \\ ${ }^{3}$ Department of Histology, University of Medicine and Pharmacy of Craiova, Romania \\ 4) Department of Internal Medicine, University of Medicine and Pharmacy of Craiova, Romania \\ ${ }^{5)}$ Department of Pharmacology, Faculty of Nursing, Târgu Jiu Subsidiary, Titu Maiorescu University, Bucharest, Romania
}

\begin{abstract}
Patients with serious mental illness are a high-risk category of severe acute respiratory syndrome coronavirus 2 (SARS-CoV-2) infection. Patients with schizophrenia are not participatory and have increased mortality and morbidity, patients with dementia cannot be cared for while depression, anxiety, bipolar tubing are associated with low immune status. Social stress is amplified by social isolation, amplifying depression and the mechanisms of decreased immunity. Hygiene measures and prophylactic behavior are impossible to put into practice in conditions of chronic mental illness. In coronavirus disease 2019 (COVID-19), the risk for severe development is associated with the presence of comorbidities and immune system deficiency. Prothrombotic status, cytokine storm and alveolar destruction are mechanisms that aggravate the evolution of patients, especially in the context in which they have dysfunction of the autonomic system. The activity of proinflammatory cytokines is accentuated by hyperglutamatergia, which potentiates oxidative stress and triggers the mechanisms of neural apoptosis by stimulating microglial activation. Activation of M1-type microglia has an important role in pathogenesis of major psychiatric disorders, such as major depression, schizophrenia or bipolar disorder, and may associate hippocampal atrophy and disconnection of cognitive structures. Memantine and Amantadine, N-methyl-D-aspartate (NMDA) glutamate receptor inhibitors, have demonstrated, through their pharmacological profile, psychotropic effects but also antiviral properties. In the conditions of the COVID-19 pandemic, based on these arguments, we suggest that they can be associated with the therapy with the basic psychotropics, Memantine or Amantadine, for the control of neuropsychiatric symptoms but also as adjuvants with antiviral action.
\end{abstract}

Keywords: SARS-CoV-2, dysautonomia, cytokine storm, inflammation, Memantine, Amantadine.

\section{a Introduction}

The infection with severe acute respiratory syndrome coronavirus 2 (SARS-CoV-2) has a large epidemic invasion power, with lethal risk for some categories of patients. Since there is no well-defined therapeutic strategy at the moment, the main measures that can influence the evolution and limit the unfavorable effects are those of social distancing and observance of hygiene rules and prophylactic behavior recommended by World Health Organization (WHO). The risk groups for SARS$\mathrm{CoV}-2$ infections identified in the existing studies until now were represented by patients with deficient immune system, old age, and multiple comorbidities (cardiovascular illness, high blood pressure, chronic lung disease, obesity, hyperglycemia).

Starting from these circumstances, we consider that patients with serious mental illness (SMI) and chronic evolution [psychotic disorders, schizophrenia, severe depression, bipolar disorder, Alzheimer's disease (AD), dementia and non-motor disorders in Parkinson's disease (PD), Lewy body dementia (LBD), other forms of dementia], represent a group of population with high risk to contract the coronavirus disease 2019 (COVID-19).
This risk is due to decreased judgement, consequent from the chronic psychiatric suffering, to decreased cognitive capacity, as well as incapacity to observe the hygiene rules, social distancing and ability to the special conditions imposed by the pandemic. Another factor aggravating the spread of the infection among this population is the hospitalization for chronic care, for long term, in psychiatric units, psychosocial or nursing homes.

The analysis of the data in literature shows that this population presents early death rate at a young age and multiple somatic comorbidities. In 2017, the USA statistical data estimated that $14.5 \%$ of adults suffer from SMI, age group prevalence being $7.5 \%$ for $18-25$ years, $5.6 \%$ for 26-49 years, and $2.7 \%$ for patients over 50 years. Out of this population group only $66.7 \%$ of cases benefited from specific psychiatric treatment in the last year [1].

The epidemiological studies performed in UK showed that the mortality rate in SMI patients is 3.7 times higher than in the general population and the deaths appear 15 years earlier. Approximately $66 \%$ of death cases could have been prevented, their major cause being the associated chronic somatic diseases, the most serious being cardiovascular and lung disease, high blood pressure, diabetes. Other major risk factors for the early deaths are the

This is an open-access article distributed under the terms of a Creative Commons Attribution-NonCommercial-ShareAlike 4.0 International Public License, which permits unrestricted use, adaptation, distribution and reproduction in any medium, non-commercially, provided the new creations are licensed under identical terms as the original work and the original work is properly cited. 
associated infections and acute respiratory illnesses, especially pneumonia. Among other early death causes are suicide, $\mathrm{PD}, \mathrm{AD}$, and other forms of dementia. The ratio between the prevalence for comorbidities in these SMI patients and the prevalence for comorbidities in the total number of patients is significantly higher for SMI in the case of obesity (1.8), asthma (1.2), diabetes (1.9), chronic obstructive pulmonary disease (COPD) (2.1), coronary heart disease (1.2), stroke (1.6), heart failure (1.5) [2]. These comorbidities are recorded as risk factors for severe evolution or death in the case of SARS-CoV-2 infection.

Besides the multiple somatic comorbidities, the schizophrenic patients smoke excessively, have respiratory dysfunctions, important cognitive deficits, a reduced social compliance, and great difficulty in observing hygiene and dietary recommendations. These particularities are associated to a distressed immunity, with major potential to trigger proinflammatory factors both at cerebral level and in the vital internal organs: heart (dilated cardiomyopathy, heart attack, chronic or acute coronary disease) and lung (COPD, multiple pulmonary infectious episodes). Due to disorganized behavior, the patients with severe mental disorders have a major risk for pulmonary diseases and infection with human immunodeficiency virus (HIV), Herpes simplex virus (HSV) type 1 and 2, hepatitis viruses, with negative impact on morbidity and early mortality $[3,4]$.

\section{口 Clinical pharmacology aspects for Memantine and Amantadine}

Memantine (derivate of Amantadine) and Amantadine are part of the adamantine class and are recognized for their psychotropic qualities, with therapeutic indications in $\mathrm{AD}$ (Memantine) and PD (Amantadine). From the point of view of the main pharmacological action, Memantine (3,5-Dimethyladamantan-1-amine) is a non-competitive antagonist for N-methyl-D-aspartate (NMDA) glutamate receptor, voltage-dependent, with moderate affinity [5]. The blockage of NMDA receptors determines the decrease of the glutamate level, mechanism that improves the neuronal excitotoxicity, induced by hyperactivity of glutamate. Other demonstrated effects of Memantine are the antagonizing of 5-hydroxytryptamine $\left(5-\mathrm{HT}_{3}\right)$ receptor and nicotinic acetylcholine receptors (nAChRs) [6]. Also, the antagonist action on the D2 dopamine receptors is similar in intensity with the one on NMDA receptors [7]. This pharmacological profile gives Memantine multiple pharmacodynamic effects, demonstrated in clinical or animal studies: the symptomatology improvement in $\mathrm{AD}$, neuroprotection, stimulation of neurogenesis, improvement of inflammatory, neuropathic or visceral pain, antiparkinsonian effect [6]. Memantine acts through multiple cellular and immunological mechanisms, slowing the neurodegenerative progress triggered by the amyloid $\beta$ $(\mathrm{A} \beta)$ and tau proteins and have neuroprotective effects. The important therapeutic benefits from major psychiatric disorders were demonstrated by the cognitive improvement and in the aggressive, psychotic, and depressive-anxious behavioral disorders.

Amantadine (1-Adamantylamine) has antiparkinsonian effect (increase dopamine levels by encouraging release and blocking reception), antiviral (especially on influenza viruses by blocking the function of M2 viral protein and impacting viral replication) and antihyperalgesic (through the anticholinergic action consecutive to inhibition of NMDA receptors) [8].

\section{a Memantine and Amantadine, psychotropic medication with antiviral action}

The surprising fact is that both substances have known antiviral effect, Memantine showing efficacy for viral infections with neurotropism, such as human coronavirus ( $\mathrm{HCoV}), \mathrm{HIV}, \mathrm{HSV}$, while Amantadine is even indication approved by Food and Drug Administration (FDA) for the prophylaxis and treatment of the infection with influenza A virus (IAV) [9, 10]. On the other hand, the infections with HIV, HSV and IAV were correlate with PD pathogenesis or parkinsonism [11], while HIV and HSV were involved in AD pathogenesis [12].

\section{Coronavirus infections}

$\mathrm{HCoV}$, including Middle East respiratory syndrome coronavirus (MERS-CoV) and severe acute respiratory syndrome coronavirus (SARS-CoV) strains, can severely affect the respiratory function, especially in the older population, with low immune system or with comorbidities and can migrate from the pulmonary level to the central nervous system. The viral neurotropism in these vulnerable groups can trigger or exacerbate encephalopathies, neurodegenerative processes, neurological illnesses, and sequelae [13]. The neurotoxic mechanisms of $\mathrm{HCoV}$ were correlated with glutamate excitotoxicity, increase in cytokine release and immune cells infiltrates [14].

Animal studies showed that the cerebral invasion of SARS-CoV virus takes place mainly through the olfactory bulb and dissemination is rapidly carried out by neuronal ways. Even though pulmonary symptomatology is not severe, a reduced viral infection can lead to death through neuronal apoptosis in cardio-respiratory centers [15]. The animal model also showed that the coronavirus infection triggers a demyelination process consecutive to inflammatory processes, aspects characteristic to multiple sclerosis. The OC43 strain of $\mathrm{HCoV}$ was identified during autopsy in $35.9 \%$ of patients with multiple sclerosis, while the seasonal model of the coronavirus infections was correlated with acute episodes in the multiple sclerosis symptomatology. The viral induced acute demyelination process comes together with the increase of tumor necrosis factor-alpha (TNF- $\alpha$ ), interleukin-6 (IL-6) and inducible nitric oxide synthase (iNOS), released especially by macrophage cells. These proinflammatory factors show high values both in chronic demyelination but through astrocytary release [16].

The HCoV-OC43 strain infection at cerebral level determined imbalances of the glutamate homeostasis through motor deficits or paralysis. Memantine administration improved the motor symptomatology, by partial recuperation of the phosphorylation function of neurofilaments and decreased the viral replication in the brain. Due to this antiviral action, Memantine can become a medication with possible indications in several neurological diseases with viral etiology [17]. 


\section{HSV infection}

The HSV infection, getting to cerebral level by retrograde axonal transport, is involved in triggering neurodegenerative processes $\mathrm{A} \beta$ aggregation and forming amyloid plaques. The HSV positive patients have a more pronounced cognitive deficit. It was demonstrated, in cell culture model and on mouse brains, that the administration of anti-HSV drugs has led to a decrease in $\mathrm{A} \beta$ and tau proteins, with a significant effect on attenuating cognitive decline. The clinical studies demonstrated the efficiency of the Valacyclovir antiviral medication in improving the memory in the schizophrenic patients and for $\mathrm{AD}$ the research is in progress $[18,19]$.

The HSV-1 infections are considered risk factors for $\mathrm{AD}$ development. The concept underlining the role played by viral infections in $\mathrm{AD}$, especially HSV-1 infection, has gained ground in the last decades. The viral determinism of AD through HSV-1 infection was confirmed in pharmacological studies that showed the antiviral efficacy of Memantine, Amantadine and Tromantadine. This antiviral action can be explained by their capacity to stop viral replication, but also by diminishing glutamatergic neurotoxicity [20]. Memantine might bring moderate benefits also in the antalgic treatment of post herpes zoster neuropathy [21], but the existing data is not conclusive due to reduced scientific information [22].

\section{HIV infection with cognitive disorders}

Approximately $50 \%$ of the HIV-infected patients will have cognitive deficit, considered in the dementia from acquired immunodeficiency syndrome (AIDS). Associating antiviral therapy with neuroprotective medication can improve the innate neuronal repair, by neuroplasticity improvement and neurological functional recovery. Memantine reduces the level of intracellular calcium and glutamate neurotoxicity, induced by the transactivator of transcription (Tat) and glycoprotein 120 (gp120) viral proteins [23].

The in vivo and in vitro studies highlighted that gp120, present on HIV-1 envelope, determines destructions and apoptosis in the neuronal cells by glutamate hyperactivation, even if the viral replication does not take place in neurons. The viral infection of microglia and astrocytes triggers neuroinflammatory, neurotoxic mechanisms and disturbance of the glutamate metabolism. An important proinflammatory marker in the HIV-1 infection, correlated with neuronal lesions and cognitive deficit, is osteopontin, having high levels in the cerebral tissue, plasma, and cerebrospinal fluid [24].

The neurotoxic effects of the HIV infection associated with dementia and encephalitis are due to the Tat and gp120 proteins in the viral structure, maintaining a high level of intracellular calcium and increasing the cytokine release with cytopathic effect. This cytopathic effect, determining the apoptosis of virus infected cells, was demonstrated also in SARS-CoV-2 [25].

Memantine succeed to block the neurotoxic effects of these viral proteins [26], leading to neuronal apoptosis also through a hyperactivation mechanism of NMDA receptors $[27,28]$. Alcohol consumption represents a risk factor for patients with cognitive deficit in AIDS because it exacerbates the gp120-induced neuronal destructions, through glutamatergic activation [29]. Memantine had effects in diminishing neuronal apoptosis induced by Tat proteins in cellular cultures for rat hippocampal neurons and stimulated neuroplasticity [30]. Also, Memantine demonstrated neuroprotective effects by diminishing the cognitive deficit in AIDS-associated dementia [31].

\section{Zika virus infection}

Memantine is in pre-approval stage with FDA for the use in the infection with Zika virus due to the capacity to reduce neuronal apoptosis, demonstrated in vitro and in mouse model [32]. This mechanism can improve the viral induced neurological symptomatology through neurotoxicity and microgliosis mechanisms [33, 34]. In studies on mice, Memantine reduced the intraocular pressure induced by Zika virus and significantly prevented the neurodegeneration and microgliosis processes [35].

\section{Influenza A infection}

Amantadine showed antiviral effects at micromolar concentration, inhibiting the IAV replication, in one of the final stages of viral ageing. In high doses, the inhibition takes place in an early replication stage, showing therapeutic effects in infections with influenza B, HSV and other enveloped viruses [36]. The efficiency rate in preventing influenza A infection was estimated between 70-90\% [37]. In influenza A, Amantadine may shorten the duration of the illness by $1.5-2.5$ days and reduce the severity of the illness [38]. These indicators recommend the administration of Amantadine, especially for the patients in the listed risk categories, the institutionalized patients and those who do not have a high protection rate following vaccination.

Association between SARS-CoV-2 and influenza infection represents a risk factor with severe evolution, reason why the prophylaxis in elder persons with Parkinson phenomena in premotor or manifested phase, not vaccinated, can be done in the current pandemic conditions with Amantadine. Amantadine [39] and Memantine [39, 40] correct the manifestations specific to dysfunction of the autonomic nervous system (dysautonomia), as well as depression and cognitive impairment in PD. It is interesting that the HCV-OC43 infections affect the dopamine synthesis in the black substance determining PD symptomatology. The PD patients had increased level of anti-coronavirus antibodies in cerebrospinal fluid [41].

\section{a Pathological aspects in SARS-CoV-2 infection}

In SARS-CoV-2 infection have been reported acute respiratory distress syndrome (ARDS) (29\%), renal insufficiency $(7 \%)$, heart failure $(12 \%)$, in these cases the cytokine storm being an unfavorable, severe prognostic factor [42]. Cases of infection with coagulation disorders and high risk of thromboembolic events have been reported $[43,44]$. Acute lung damage from alveolar destruction, following high levels of proinflammatory cytokines, has been observed in infections caused by influenza viruses [45], and SARS-CoV [46]. Some patients, who have lung damage through the destruction of alveolar lung cells, also have acute heart damage (myocardial infarction, cardiac arrest). Among deceased patients who did not have pre-existing cardiac pathology, $11.8 \%$ developed 
major heart damage after infection. The onset of heart failure following acute lung injury has been explained by several mechanisms: involvement of angiotensin-converting enzyme 2 (ACE2) receptors, cytokine storm, respiratory failure, and hypoxia [47].

Since the asymptomatic phase of SARS-CoV-2 infection, neurological signs have been identified, such as loss of smell and taste, neuralgia, myalgia [48]. Also, in some cases, epileptiform seizures have been described, which could be caused by neuronal invasion, hypoxia, organ failure or drug induction [49]. There may be other mechanisms caused by increased excitability of cortical and subcortical neurons, correlated with microglial activation, glutamatergic hyperactivity, blood-brain barrier (BBB) disruption and high levels of cytokines that may anticipate the risk of epileptic seizures. The seizures are associated with an increase in IL- $1 \beta$ and TNF- $\alpha$ [50]. Therapies with NMDA receptor blockers reduce levels of these cytokines, with a strong antiepileptic effect [51].

There have been reports of severe forms of COVID-19, seizures, confusion and even strokes that may be correlated with cerebral oxygenation deficiency but also with increased neural excitability following cytokine aggression. Neurological symptoms were present in $36.4 \%$ of patients with COVID-19 and in $45.5 \%$ of patients with severe infection [52]. These data show the importance of decreased olfactory acuity and polyneuropathic pain as the disease progresses. The generalized hyperalgesia condition in COVID-19 may be correlated with the hyperexcitability of the glutamatergic system and may be a valuable clinical sign of predicting severe evolution. Blockade of NMDA receptors can improve pain relief by increasing the neuroprotective effect in the brain and significantly decreasing the state of central and peripheral neuronal excitability following cytokine hyperactivity.

Neuronal invasion is a severe prognostic factor in respiratory progression, which can go as far as death by spreading the virus to the cardiorespiratory centers [53]. This clinical picture of the neurological type that appeared in viral infections signals the neuronal viral invasion and the transition to central nervous system symptoms. Due to the viral neurotoxicity, dysautonomia is accentuated, probably by involving the regulation mechanisms at the bulbar and pontine level. In our opinion, the neurological manifestations are favored by the existence of dysautonomia, similar to the non-motor symptoms in the prodromal phase of PD.

Olfactory disorders may be quantitative, characterized by global hyposmia induced glutamatergic aggression on the olfactory bulb and olfactory circuits, and a qualitative decrease in olfactory discrimination capacity determined by olfactometry, correlated with decreased dopamine levels. Olfactory dysfunctions are also reported in the prodromal phases of $\mathrm{PD}$, associated with a series of nonmotor phenomena that precede motor phenomena by several years: odor loss and signs of autonomic system dysfunction [54]. Some clinical features, such as constipation, erectile dysfunction and orthostatic hypotension, may occur 10-16 years before PD, in the preclinical phase and delay the diagnosis. In the symptomatic prodromal phase may occur: pupillary hypersensitivity, sialorrhea, thermoregulatory disorders (hyperhidrosis and on the contrary dry skin, hyperthermia or chills hypothermia with changes in heart rate), gastrointestinal, urinary or cardiovascular disorders (supine hypertension, postprandial hypotension) [55]. The atypical forms of COVID-19 onset may be correlated with dysautonomia that disrupts the functionality of the gastrointestinal system or through gastroparesis, neuropathies of the intestinal vegetative plexuses, and altered gut-brain barrier [56, 57].

In this context, a pathogenic mechanism of the "vicious circle" type can be supported, the dysautonomia favoring the appearance of neurological clinical manifestations and the cerebral pathogenic support, and this accentuates the dysautonomia. The importance of this syndrome in the PD model becomes important in clinical psychiatry due to the similarity of this model with the manifestations of drug or vascular parkinsonism that can be found in most chronic SMI. For schizophrenia, the theoretical perspective of the neurobiological model highlights the presence of "soft" extrapyramidal signs, a phenomenon that suggests in this category of patients the vulnerability to dysautonomia $[58,59]$.

\section{ㅁ Clinical manifestations associated with dysautonomia}

\section{Orthostatic intolerance syndrome}

Dysautonomia, since the asymptomatic phase of SARS-CoV-2 infection, is associated with orthostatic intolerance syndrome characterized by decreased orthostatic blood pressure associated with chronic fatigue syndrome, dizziness and balance disorders, tachycardia, and vasovagal syncope [60]. Orthostatic intolerance syndrome causes orthostatic stress that increases prothrombotic state [61]. In orthostatic intolerance syndrome associated with repeated syncope, a significant increase in von Willebrand factor has been reported [62].

On the other hand, prothrombotic status is associated with increased endothelial activation factors and plasma protein and hematocrit concentration, as well as decreased C-reactive protein. Increased activity was observed for several factors involved in coagulation: fibrinogen, von Willebrand factors, V and VIII, prothrombin fragments 1 and 2 [63]. These biological markers can identify the risk of hypercoagulability syndrome caused by orthostatic stress under dysautonomia since the asymptomatic stage of COVID-19. Dysautonomia with noradrenergic hyperactivity and sympathetic dominance is associated with arteriole and venous vasoconstriction in the cerebral, coronary territory but also at the level of the pulmonary or renal systems, this mechanism being able to favor multisystemic thrombosis.

\section{Glaucoma}

The prevalence of glaucoma in PD is estimated at $16-24 \%[64,65]$. In conditions of glaucoma, especially in the form of a closed angle, a headache may occur accompanied by eye pain and redness, nausea, and vomiting, and may mimic a SARS-CoV-2 onset. Glaucoma can also trigger progressive optic neuritis. Dysautonomia is associated with glaucoma, the intensity of dysautonomia involved in the pathogenesis of glaucoma can be correlated with the intensity of changes in pupillary contractility 
objectified by dynamic pupillometry tests. This marker indicates the risk of developing antineutrophil cytoplasmic antibodies (ANCA) syndrome associated with the high potential for ANCA-associated vasculitis (AAV) [66, 67]. AAV is an evolutionary risk indicator in patients with renal failure and dialysis, a risk that can be correlated with the intensity of dysautonomia clinical-biological indicators. In elderly patients and dialysis, the increase in ANCA may be an indicator of evolutionary risk to endstage renal disease [68]. In the conditions of the SARV$\mathrm{CoV}-2$ pandemic, we consider that special protocols are required for the safety of these patients, with a high risk of unfavorable evolution.

The neuroprotective action in conditions of autoimmune mechanisms that can trigger optic neuritis has been reported using experimental translational blockers for NMDA receptors. The administration of Memantine stops the demyelination process of the optic nerves, reduces the apoptosis of the cells in the retinal ganglion and improves the clinical symptoms by reducing the inflammatory infiltrates that will cross the BBB. The increased inflammatory status located in the optic nerves has been correlated with high levels of glutamate in the retina $[69,70]$.

In the conditions of an asymptomatic infection with SARV-CoV-2, the identification of the triad composed of dysautonomia, a symptom of orthostatic intolerance with hypotension and changes in dynamic pupillometry, indicates the state of evolutionary risk. The appearance of plasma indicators that anticipate hypercoagulability requires urgent prophylactic intervention, with anticoagulant pharmacological treatment. This possible mechanism (multisystemic thrombosis) may be involved in explaining sudden deaths in quarantined patients (home deaths) and the risk of death in relatively young patients with no clear evidence of other comorbidities.

Progressive optic nerve neuropathy associated with glaucoma may have an autoimmune component that explains the favorable response in translational studies to intravitreal administration of Memantine [71-73]. The identification of glaucoma in patients with mental illness becomes important because it signals a negative evolution of SARS-CoV-2 infection, and on the other hand glaucoma can be induced or exacerbated by psychotropic medication $[74,75]$.

\section{Myalgia}

Viral aggression can be announced in a first phase of the toxic state, with general condition deeply altered, with myalgia type of autonomic neuropathy with viral toxic component. Another theoretical pharmacological argument that supports our hypothesis is that these myalgias are little influenced by the usual analgesic medication indicated in therapeutic protocols, instead Memantine and Amantadine have positive studies to control myalgia from HSV infection and fibromyalgia.

Myalgia associated with viral infection may be present in the asymptomatic phase of the disease and requires, especially in patients with pre-existing psychiatric disorders, the differentiation of fibromyalgia from depressive syndromes that can be amplified by stress caused by conditions of social isolation. Persistence of pain may promote the development of depression in patients without a psychiatric history, or autolytic behavior in patients with depressive disorders. Thus, the depressive syndrome after HSV infection in the elderly is triggered by neuralgia, which is why the pain syndrome is sometimes included in fibromyalgia. The viral origin of the pain is also confirmed by the very good therapeutic response to the association between Pregabalin and Memantine [76].

In SARS-CoV-2 infection appears the pain syndrome, predominantly muscular, which can be caused by the phenomenon of autonomic peripheral neuropathy and glutamatergic hyperactivity. Also, in the pathogenesis of persistent pain, the hyperglutamatergic mechanisms are involved. NMDA receptor blockade, on the model of Ketamine and Memantine, has shown positive results in the control of neuropathic pain [77-80]. Based on this hypothesis, the use of an NMDA blocker that also has antiviral action, could bring therapeutic benefits in the management of COVID-19.

\section{Cardiovascular clinical manifestations}

Hypertrophic cardiomyopathy syndrome associates dysautonomia with an imbalance alternating between the parasympathetic and sympathetic systems. The predominance of parasympathetic activity associated with ventricular hypertrophy in essential familial or primary hypertrophic cardiomyopathy and expresses a high risk for severe ventricular arrhythmias. The predominance of the sympathetic system is associated with hypertension and ventricular hypertrophy due to the tendency of arterial spasm can frequently cause acute coronary syndromes. It is important to identify hypertrophic cardiomyopathy in the elderly with cognitive impairment and predominantly parasympathetic activity, because the use of acetylcholinesterase inhibitors can cause arrhythmia and sudden death [81].

Takotsubo syndrome (TTS) is characterized by an acute dysfunction of the left ventricle triggered by conditions of emotional or physical stress. This syndrome supports the presence of autonomic dysfunction and altered connections with the limbic system by altering the brainheart axis [82].

Dysautonomia preceding PD also affects the cardiovascular system. Myocardial scintigraphy correlated with postural hypotension in the premotor phase of PD can announce with a probability of up to $90 \%$ the onset of PD. ${ }^{123}$ I-metaiodobenzylguanidine (MIBG) myocardial scintigraphy showed a decrease in sympathetic innervation of the heart associated with the tendency for dilated cardiomyopathy [83-85].

PD and parkinsonism are frequently associated with pulmonary complications: airway obstruction, hypophonia, sleep apnea, pleuro-pulmonary fibrosis, decreased ventilation, aspiration pneumonia, and other complications associated with decreased regulation of central respiratory muscle strength. Because of this, in the early stages of PD and parkinsonism, there is a ventilatory dysfunction with increased $\mathrm{CO}_{2}$ and a decrease in red blood cell load with $\mathrm{O}_{2}$. The reduction of the functional respiration capacity is also associated with cognitive deficit, conditions in which the vulnerability for viral or microbial pneumonias appears $[86,87]$. 
Respiratory disorganization is significantly altered in patients with PD, especially by affecting the cardiac sympathetic system, with a predisposition to atrial fibrillation that is responsible for pulmonary, cerebral or small vessel thromboembolic events. Both in parkinsonism and in the early non-motor phases of PD, there are multiple conditions that favor premature death, such as pneumonia, brain or cardiovascular disease, cardiac arrhythmias, cardiac conduction disease, which can cause sudden unexpected death in Parkinson's disease (SUDPAR) [88].

Cardiovascular protection of Memantine can be argued based on the evidence of cardiac and vascular NMDA receptors [89, 90]. Animal studies have shown that Memantine has a myocardial protective effect by stopping proinflammatory events following lipid peroxidation, with decreased malondialdehyde (MDA) and reducing neutrophil invasion in the heart [91].

\section{ㅁ Neurological clinical manifestations}

The most common neurological manifestations in COVID-19 are decreased or lost sense of smell, accompanied by loss of taste, neuronal hyperexcitability syndromes due to increased glutamate activity, such as rapid eye movement (REM) sleep behavior disorder or epileptic seizures.

\section{Olfactory dysfunction}

Olfactory dysfunction can be triggered by HSV-1 and HSV-2 infections, Chlamydia pneumoniae, spirochetes and other bacterial infections, raising the issue of pathogenic associations between two or more concomitant viral diseases. Unfavorable evolution may be a consequence of these infectious conditions.

In elderly patients, dopamine deficiency may be associated with the onset of motor symptoms in PD and cognitive impairment but also with decreased ability to discriminate olfactory sense. The decrease in the number of dopamine receptors in the olfactory bulb demonstrates the involvement of dopamine in olfactory acuity. Because the olfactory bulb is a dopamine-controlled structure, decreased olfactory performance, especially odor discrimination, may be a first sign of non-motor onset of PD [92].

The decrease in olfactory dysfunction may anticipate a rapid evolution from the mild cognitive impairment (MCI) stage to $\mathrm{AD}$, but it can also be a marker for a negative evolution in schizophrenia, through the involvement of dopamine [93]. Decreased olfactory acuity on translational research is considered a valid pathogenic model for both AD and PD. The olfactory bulbectomy performed in rats showed, in addition to a decrease in cognitive abilities, a 300\% increase in homocysteine. Also, at the plasma level, the proinflammatory cytokine factors were much increased, especially IL- $1 \alpha$ and IL- $1 \beta$, IL- 6 and TNF- $\alpha$. Given the occurrence of olfactory deficit in the asymptomatic phase of SARS-CoV-2 infection, these markers may suggest the installation of acute respiratory syndrome, which is why early prophylactic intervention measures are required [94].

The neuroprotective and cognitive-enhancing effect of Memantine in rats with olfactory bulbectomy has been demonstrated [95]. On the other hand, the beneficial role of Memantine may be correlated with NMDA receptor blockade and the possible relationship between NMDA receptors and the brain renin-angiotensin system (RAS) in $\mathrm{AD}$ and PD [96]. Angiotensin II enhances NMDA activity and increases the production of reduced nicotinamide adenine dinucleotide phosphate (NADPH) oxidase 2 (NOX2)-dependent superoxides in paraventricular neurons located in hypothalamus [97].

\section{Gustatory dysfunction}

Decreased taste to total loss is a neurological syndrome that suggests the aggressiveness of viral infection with SARV-CoV-2, because from the points of emergence and cantonment of the virus in the nasal mucosa, tongue, and oropharynx, through the ascending pathways, reaches the nucleus of the solitary tract located in the medulla oblongata. From here, the neural connections are ascending and connect the ventral posteromedial nucleus located in the thalamus and gustatory cortex of the frontal lobe, consisting of the anterior insula and the frontal operculum. Bulbar projection may be associated with a major risk of respiratory arrest, a consequence of inflammatory processes secondary to viral neurotoxicity (proinflammatory edema) [98]. This mechanism may explain rapid and severe respiratory failure in some COVID-19 patients, especially those who have had the onset of hyposmia disease [99].

\section{REM sleep behavior disorders}

REM sleep behavior disorders can have a psychiatric appearance due to aggressive manifestations during REM sleep. This disorder may have idiopathic determinism occurring in the context of neurodegenerative neurological disorders: PD, multiple system atrophy, LBD. The pathogenesis of the disease has been correlated with dopamine deficiency and favorable results have been reported with Amantadine treatment [100]. In PD, during the prodromal period, a specific syndrome occurs with sleep disorders and eye movements, with a high risk of mortality due to coronary vascular mechanisms [101]. The particular character of this syndrome in the conditions of COVID-19 infection can lead to an atypical onset of psychiatric or neurological aspect.

\section{Epileptic symptoms}

Epileptic manifestations may be associated in psychiatric clinical practice with glutamate system hyperactivity and increased excitability of neural systems, amid decreased efficiency of gamma-aminobutyric acid (GABA) inhibitory transmission. This symptomatology can be identified in the history of patients with schizophrenia, following hypoxic-ischemic encephalopathy (HIE). In these patients, there is a primary hyperglutamatergic activity and the presence of febrile convulsions or epileptic manifestations in the first year of life may be a risk factor for schizophrenia. Vulnerability for epileptic manifestations and primary hyperglutamatergia is associated with symptoms of dysautonomia [102]. This link may justify the administration of selective NMDA receptor blockers, as Memantine, to control dysautonomia and epileptic symptoms. In the conditions of SARS-CoV-2 infection, proinflammatory mechanisms triggered by M1-type microglial activation are associated, the presence of which can anticipate an unfavorable prognosis. 


\section{a Pathogenic mechanisms with evolutionary risk, specific to SARS-Cov-2 infection}

\section{Prothrombotic state}

The prothrombotic state, favored by dysautonomia and other comorbidities, can generate alteration of selfregulation mechanisms and maintenance of immune homeostasis with the onset of cytokine storm. Increased serum levels of fibrinogen, von Willebrand factors, V and VIII, announce a severe evolution and a high risk of mortality [103]. Atherothrombotic events can be induced by increased cytokine activity, especially IL-1, IL-6, and TNF- $\alpha$, by exacerbating endothelial dysfunction, decreased collagen synthesis, and activating the blood clotting processes. This mechanism may explain the lack of therapeutic response to anti-inflammatory medication and the atheroprotective effects of targeted anti-cytokine therapy [104]. Atherothrombosis is associated with hypertension, dysautonomia and increased activity of hemostatic factors that promote thrombogenesis, causing a lethal risk in patients infected with SARS-CoV-2. On the other hand, thrombotic events, vascular inflammatory phenomena, and endothelial dysfunction are accentuated by the RAS $[105,106]$.

\section{Cytokine storm}

The second pathogenic mechanism involved in the severe evolution of acute respiratory syndrome in SARSCoV-2 is cytokine aggression. The rapid increase in proinflammatory cytokines, especially IL-6, IL- 1 , TNF- $\alpha$, and interferon (IFN), triggers cytokine storms, which cause endothelial dysfunction, vascular barrier damage, alveolar damage, and multiple organ failure [107]. Controlling the immune response and inflammatory processes is extremely important in reducing the severity of the disease and the risk of death [108].

Memantine has evidence for its important role in balancing cytokine mechanisms, confirmed by studies on animal models, but also in clinical trials for depressive disorder in type 2 bipolar disorder. A randomized, doubleblind clinical study of the efficacy of Memantine in combination with Valproic Acid (VPA) in patients with type II bipolar disorder revealed a significant decrease in the TNF- $\alpha$ cytokine marker in the group with VPA + Memantine vs. VPA + placebo [109]. This effect can be explained by the fact that cytokine aggression is mainly triggered by the imbalance in the excitatory glutamatergic system, which is hyperactive, and the inhibitory GABA system, which is deficient. Glutamatergic hyperactivity favors the onset of inflammatory mechanisms and implicitly an exaggerated increase in the level of cytokines in the peripheral blood but also through the M1 microglial activation of cytokines with destructive action [51, 110, $111]$.

In the animal model, cognitive impairment induced by okadaic acid was associated with increased aggressiveness of the TNF- $\alpha$ and IL- $1 \beta$ proinflammatory cytokines and increased total nitrites in the cortex and hippocampus. The levels of NO synthesis proteins were altered, the neuronal NOS (nNOS) isoform being low, and the iNOS isoform being increased. Oxidative stress has been demonstrated by elevated levels of reactive oxygen species (ROS) and mitochondrial calcium in the brain [112].

Prophylactic administration 13 days before of Memantine associated with Donepezil, had a protective effect, thus demonstrating the involvement of neuroinflammatory processes in the onset or worsening of cognitive deficit $[113,114]$. On the other hand, the important effect of Memantine in reducing cerebral vasospasm and in ameliorating endothelial dysfunction by restoring endothelial NOS (eNOS) functionality has been demonstrated [115]. nNOS is found predominantly in central and peripheral neurons, having a role in synaptic plasticity, central blood pressure regulation and smooth muscle relaxation. iNOS is a pathogenic factor for several inflammatory conditions, being expressed in cells involved in the cytokine response and associated with septic shock. eNOS, through its presence in endothelial cells, has effects in regulating blood pressure, vascular protection, in reducing atherosclerotic processes and in avoiding apoptosis induced by proinflammatory cytokines. Balancing eNOS and relieving oxidative stress can be done with the help of angiotensin and renin conversion enzyme inhibitors as well as angiotensin receptor blockers [116].

\section{Alveolar dysfunction}

Aggression in the alveolar tissue causes severe damage to the alveolar epithelium. Through single-cell ribonucleic acid (RNA)-seq analysis, the role of the development of lung alveolar type I (AT1) cells. AT1 was demonstrated both during the postnatal evolution of the lungs and in alveolar regeneration. This type of alveolar cells is present in $95 \%$ of the alveolar surface, ensures the integrity and proper functioning of the airblood barrier but contributes to maintaining the plasticity of cell development in the process of alveolar regeneration. The presence of insulin-like growth factor-binding protein 2 (IGFBP2) in AT1 cells is a valuable marker, which increases during alveologenesis and in the post-pneumonectomy repair process $[117,118]$.

Cytokine storm triggers dysfunctional but hyperaggressive immune mechanisms, with direct destructive action on the alveolar cell. Translational research on animal models has objectified the protective role in the pulmonary alveoli of Memantine against substances with destructive aggression in the alveolar level. Lung damage characterized by pulmonary edema and leukocyte infiltrates was caused by increased cytokines and oxidative stress. By blocking NMDA receptors in the lungs, Memantine has led to a decrease in the inflammatory response and oxidative stress, with a decrease in lung damage. In the animal model, Memantine can stop the inflammatory process in the lungs in mice by inhibiting the release of proinflammatory factors such as TNF- $\alpha$, IL-6 and IFN- $\gamma$ [119]. In addition, Memantine can increase the resistance of the alveolar barrier to the destruction of destructive factors (Bleomycin) and prevent the increase of oxidative stress, an important pathogenic factor of the destruction of the alveolar barrier, by reducing the oxidative marker MDA [120].

SARS-CoV-2 aggression on the central nervous system may be associated with increased cytokine storm intensity as the mechanism of activation of microglial structures 
occurs. The cytokine mechanisms are triggered by the activation of M1-type microglia, which trigger the production and high release of proinflammatory cytokines IL-1, IL-6, TNF- $\alpha$, NO and ROS, to the detriment of neuroprotective M2 microglia, whose activity is related to anti-inflammatory cytokines IL-4, IL-10, IL-13 and transforming growth factor-beta (TGF- $\beta$ ) [93, 104, 121]. The imbalance ratio M1/M2 microglia have an important role in pathogenesis of major psychiatric disorders, such as major depression, schizophrenia or bipolar disorder [122]. At the same time, long-term M1-type microglial activation may associate hippocampal atrophy and disconnection of cognitive structures [123]. For this reason, in the long term, SARS-CoV-2 infection may cause cognitive deficits, which may be a pathogenic mechanism of triggering AD or PD by neurotoxic viral action.

\section{ㄷ Effectiveness of Memantine and Amantadine in SMI treatment}

The positive therapeutic effects of Memantine and Amantadine obtained in the treatment of patients with SMI, are pharmacological arguments to support the possible efficacy of these two psychotropic drugs in the prophylactic use for SARS-CoV-2 infection in this category of patients. Control of psychiatric symptoms may reduce the risk of infection and disease transmission, and on the other hand, reducing the effects of the pathogenic mechanisms of SARS-Cov-2 may decrease cases with a risk of severe evolution or death.

\section{Schizophrenia}

The efficacy of Memantine in schizophrenia has been demonstrated in clinical trials in which Memantine has been associated with antipsychotic treatment in patients with chronic disease [124], cognitive deficits [125], predominance of negative symptoms [126, 127], or in patients with positive and negative symptoms [128]. Patient aggression is associated with glutamate hyperactivity, and the use of Memantine in combination therapies has been based on the glutamatergic hypothesis of schizophrenia and the major role played by NMDA receptors [129]. Glutamatergic hyperactivity potentiates oxidative stress, activates ion channels for calcium, sodium, and potassium, triggering excitotoxicity mechanisms that stimulate microglia activation in the brain and peripheral causing a true destructive cytokine storm. Oxidative stress accentuates the mechanisms of neural apoptosis, and in association with cerebral circulatory disorders, promotes the development of atrophy of the hippocampus, cerebral amygdala, and frontal cortex, with the occurrence of residual symptoms of schizophrenia [130].

Under COVID-19 conditions, the severe course of the disease can be explained by the mechanism of cytokine storm that produces neuronal apoptosis followed by cortical atrophies, destruction of the neurovascular and astroglia unit and significant endothelial dysfunction with decreased cerebral vascular perfusion (stroke risk), as well as at the level of the coronary territory (risk of infarction), renal (renal insufficiency) or of the alveolar capillary (alveolar destruction). Treatment with Memantine in combination with antipsychotics, in patients with schizophrenia significantly decreased TNF- $\alpha$ proinflammatory factor and the negative symptoms [131].

In addition to immune mechanisms, the risk of severe evolution can also be correlated with dysautonomia, following drug-induced parkinsonism. If schizophrenia is frequently correlated with a neurodevelopmental etiopathogenesis, dysautonomia may be primary [59]. In addition, it is hypothesized that in patients with schizophrenia who have a history of neurodevelopmental abnormalities or parkinsonism disorders within the neurological soft sign class, prior to any psychotropic therapy, greatly increases the risk of central nervous system symptoms in conditions with SARS-CoV-2.

Dysautonomia in schizophrenia is associated with multiple comorbidities, such as diabetes, cardiometabolic syndrome and obesity, which leads to a significant cardiocerebrovascular risk [132]. On the other hand, antipsychotic therapies can induce cardiometabolic syndrome, diabetes, QT changes, but also agranulocytosis and leukopenia $[133,134]$. The high level of homocysteine can be considered a marker of negative evolution of neurodegenerative type. In patients with schizophrenia and COVID-19, homocysteine increases coagulability with a risk of thrombosis and leukopenia and agranulocytosis favor secondary bacterial or viral infections, which is why the combination of these two conditions causes a high risk of early mortality.

\section{Depression}

Depression has a biological mechanism dominated by hypothalamic-pituitary-adrenal (HPA) axis hyperactivity, with increased cortisol, patients being prone to decreased immunity and multiple somatic complications on an inflammatory background. Cytokine mechanisms are more strongly expressed in bipolar depression. Due to a high rate of incomplete remissions, patients with unipolar or bipolar depression may be considered at risk for SARSCoV-2. Memantine infection and Ketamine has demonstrated antidepressant effects, by extrasynaptic inhibition of NMDA receptors (Memantine) or by synaptic inhibition of these receptors (Ketamine) [79]. Memantine therapy combined with other antidepressant or anxiolytic medications could have a prophylactic effect in SARS-CoV-2 pandemics. Depression can be a consequence of the social stress associated with the COVID-19 pandemic and especially of the economic losses following the pandemic.

In addition, Memantine has efficacy studies for bipolar disorder [135], depression in bipolar disorder [136], depression in schizophrenia [137] and treatment-resistant depression [138]. This efficacy is correlated with the specific modulatory effect of NMDA receptors and hyperglutamatergia is involved in the biochemical pathogenesis of these diseases [139].

Ketamine has a strong and rapid antidepressant effect, managing to rebalance the cellular mechanisms of proinflammatory cytokine and endothelial dysfunction, in resistant depression or in depressions with incomplete response [140]. Ketamine also reduced the rate of suicide in cases of treatment-resistant depression [141]. The $S(+)-$ enantiomer of Ketamine (Esketamine) received in 2019 $F D A$ approval for the treatment of resistant depression associated with an oral antidepressant medication [142]. 
Depressive disorder is an evolutionary risk factor in SARS-CoV-2 infection, due to the presence of dysautonomia that can be triggered by hypercortisolemia induced by HPA axis hyperactivity, which causes overstimulation of the coeruleus locus and massive release of norepinephrine with sympathetic hyperactivity. Dysautonomia may also be due to extrapyramidal phenomena of parkinsonian type induced by mood stabilizers medication, selective serotonin reuptake inhibitors (SSRIs) or serotonin and norepinephrine reuptake inhibitors (SNRIs) antidepressant, or antipsychotics with antidepressant effect.

Depression from bipolar type 2 disease causes significant changes in cytokines, while high levels of cytokines especially brain-derived neurotrophic factor (BDNF), IL-2, IL-6, and TNF- $\alpha$ induce or amplify depression $[143,144]$. The mechanism by which depression promotes the inflammatory process and triggers the cytokine storm is directly related to excess glutamate, which may be corrected by Memantine. Another argument that correlates the cytokine storm with the onset or exacerbation of depression is the significant antidepressant effect of anti-cytokine medication in patients with chronic inflammatory process, an effect demonstrated in a metaanalysis [145].

Depressive disorder may be present in the prodromal stages of AD. Treatment of AD prodromal depression with Memantine and Escitalopram had positive results $[146,147]$. In major depressive disorder, treatment with Memantine in combination with Sertraline improved depressive symptoms and had a good safety profile [148]. Depression in the non-motor prodromal stage of $\mathrm{PD}$ is dopamine-dependent and does not respond to antidepressant medication, but NMDA antagonists may have benefits in reducing psychiatric symptoms [39]. Therapeutic responses may be obtained with Amantadine [149, 150].

In patients with depression and COVID-19, cytokine storms can be triggered rapidly, which is why proper and early antidepressant treatment is extremely important. At the same time, depression favors prothrombotic status, inflammation and oxidative stress, mechanisms that in the context of SARS-CoV-2 infection induce a severe evolution, with a high risk of death [151]. The connection between the RAS and depression and the presence of ACE2 receptors in the brain should also be considered. Inhibition of RAS activity had positive effects in neurogenesis, with decreased oxidative stress and inflammatory processes [152].

\section{Alzheimer's disease}

There are arguments that may support the role of infections in accentuating the neurodegenerative mechanisms of AD since there is an association between HSV infection and apolipoprotein E4 (APOE4) spectrum, especially in patients with cytomegalovirus, but also in patients whose other respiratory infections: influenza A and B, Chlamydia, group B streptococcus, Mycoplasma pneumoniae [153, 154]. The involvement of multiple infectious factors in the elderly's cognitive deficit can also be explained by impaired immunity. Respiratory infections can be considered a risk factor for the progression of dementia, and dementia can be a risk factor for the severe course of a lung infection. These aspects are not fully confirmed, being supported by some authors, and denied by others, but certainly, in nursing home care conditions, the mortality of patients with $\mathrm{AD}$ and lung infections is high [155, $156]$.

Astrocytes have a major role in triggering the neurodegenerative mechanisms in AD and PD [157]. Astrocytes influence the modeling of brain damage, by increasing the release of glutamate, GABA, and inflammatory factors, as well as by astrogliosis with the formation of glial scars. Elevated levels of cytokines responsible for the neuroinflammatory response have been identified in the brain affected by $\mathrm{AD}$, for IFN- $\gamma$, IL- $1 \beta$, TNF- $\alpha$, IL- 6 and TGF- $\beta$. Cellular stressors increase the number of reactive astrocytes that amplify $\mathrm{A} \beta$ synthesis. This mechanism is correlated with the innate immune response, and it has been shown that $\mathrm{A} \beta$ has an antimicrobial peptides (AMPs) role in the brain [158]. AMPs act on several categories of external pathogens, including bacteria, fungi, and viruses [159].

The action of $\mathrm{A} \beta$ as AMP has been explained by the ability to form extracellular neurofibrils that can encompass viral pathogens. $\mathrm{A} \beta$ overproduction has been associated with high resistance to viral or bacterial infections, while blocking $\mathrm{A} \beta$ synthesis in Alzheimer's patients has been correlated with high infection rates [160]. Two of the $\mathrm{A} \beta$ isoforms, the 42 -residue $\mathrm{A} \beta 42$ and the 40 -residue $\mathrm{A} \beta 40$, have an antiviral effect for enveloped viruses with cerebral affinity such as HSV-1, which may explain the infectious cause of amyloid plaque formation, with a risk of $\mathrm{AD}$ progression [161].

It has been shown in vitro that $\mathrm{A} \beta 42$ and $\mathrm{A} \beta 40$ inhibited IAV replication types $\mathrm{H} 3 \mathrm{~N} 2$ and $\mathrm{H} 1 \mathrm{~N} 1$, by blocking the entry of viruses into epithelial cells, favoring entry into neutrophils, inhibiting the replication of viral proteins in monocytes, and decreased virus-induced IL-6 synthesis [162]. Overproduction of $\mathrm{A} \beta$ has also been shown in HIV infection by the accumulation of $\mathrm{A} \beta$ in plaques or intraneuronal in the frontal cortex [163].

Oxidative stress and neuroinflammatory processes triggered by cytokine activation may have an excitotoxic effect through the action of quinolinic acid from tryptophan metabolism. The protective effect of Memantine has been demonstrated in hippocampal cell cultures from Wistar rats by reducing the apoptosis of neurons and astrocytes due to the antagonistic effect of NMDA receptors [164]. Memantine may have antiparkinsonian effects because it prevents the in vivo and in vitro death of brain neurons damaged by excitatory amino acids. These acids are involved in triggering neurodegenerative processes in parkinsonism and dementia in AIDS. Memantine in rats prevented the destruction of retinal ganglion cells triggered by NMDA receptor activation [165].

A major role in the rapid evolution of cognitive impairment in $\mathrm{AD}$ and $\mathrm{PD}$ is played by cerebral vascular dysfunction. The presence of symptoms of dysautonomia and especially orthostatic hypotension by decreasing cerebral perfusion, accentuates cognitive impairment. The use of hypotensive medication in the elderly with dementia must be personalized and correlated with some pharmacological mechanisms, because the ROS system is an important pathogenic mechanism in dementia in $\mathrm{AD}$ and $\mathrm{PD}[166,167]$. 


\section{$\square$ Vulnerability of patients with SMI to SARS-CoV-2 infection}

Considering the high incidence of major mental disorders and their association with multiple comorbidities, correlated with the inability of patients to self-care, the risk of SARS-CoV-2 infection is amplified, as well as severe evolution. Schizophrenia correlates with cognitive deficit, major impairment of self-care and non-compliance with hygiene measures, social distancing, and isolation. Depressive disorders worsen under conditions of social stress and social isolation and are associated with a low immune status and a high potential for increased mechanisms of cytokine activation. Anxiety is amplified by the implementation of restrictive measures related to the pandemic and causes biochemical changes related to hyperactivation of the HPA axis, with increasing levels of endogenous cortisol and proinflammatory cytokines. Patients diagnosed with $\mathrm{AD}$, vascular dementia or other forms of dementia are a major risk category for SARSCoV-2 infection due to age, cognitive deficit, comorbidities, and dependence on specialized care.

Due to these reasons, Memantine or Amantadine therapy, possibly combined with melatonin for sleep disorders or Valacyclovir for viral infection, can decrease the incidence of contamination by improving mental status, increasing self-care but also by prophylaxis of comorbid events with unfavorable evolution in case of infection with SARSCoV-2. The use of Memantine could be a means of preventing the negative evolution in patients positive for SARS-CoV-2, asymptomatic or with minimal symptoms, who have a history of depressive episodes or who have depressive anxiety in conditions of pandemic reactive stress. The use of Memantine could also be facilitated by the low rate of side effects and very good tolerance. Short-term administration (14-21 days) in these categories of patients, especially those in isolation or quarantine, could be beneficial.

Amantadine could be used in combination with influenza A infections with SARS-CoV-2. Recognition of the patient population with SMI and chronic evolution as a risk group for SARS-CoV-2 infection and the major potential for adverse outcome should become a priority of mental health strategies in the COVID-19 pandemic. At the same time, patients with SMI can also be vectors of transmission and maintenance of the pandemic condition. Their inclusion in a program for the prevention of SARS-CoV-2 infection, as well as the prevention of the major risk of unfavorable evolution, may be a second major priority of public health strategies. The use of Memantine and Amantadine in these prophylaxis programs can be confirmed in further studies or by repeated testing of the patient population with hospitalized mental illness and at risk of SARS-CoV-2 infection.

Prophylactic or therapeutic recommendations can be made based on the effectiveness of Memantine in schizophrenia, elderly depression and bipolar depression, anxiety and treatment-resistant depression, and cognitive impairment in $\mathrm{AD}$ and other forms of dementia. The administration of Memantine can be done during the quarantine or isolation period and continued during the persistence of the risk of contamination. The effectiveness of these recommendations can be confirmed or refuted by further studies or by repeated testing of the patient population with SMI and the risk of SARS-CoV-2. The possible specific antiviral efficacy in COVID-19 of early Memantine therapy in the asymptomatic phase may be questioned, especially in patients with decreased olfactory acuity and generalized hyperalgesia syndrome. Olfactory decrease (dependent on increased glutamate activity) and odor discrimination (related to dopamine deficiency) are non-motor signs that may precede the onset of PD. The presence since the asymptomatic stage of SARS-CoV-2 infection of multiple pain manifestations (myalgia, fibromyalgia) and loss of smell and taste, suggests the neuroinvasive potential of the virus, a tendency that can be prevented or controlled by Memantine.

\section{a Conclusions}

Memantine and Amantadine represent, from the point of view of the clinical psychopharmacologists, a therapeutic alternative in COVID-19 associated with major psychiatric pathology. Due to comorbidities, patients with chronic SMI have an increased and early mortality. Many cases of sudden death can be explained by dysfunction of the autonomic system, which causes cardiovascular and cerebrovascular changes and a complex symptomatology that includes constipation, visual deficit, visual hallucinations, sleep disorders. For all the evolutionary risk mechanisms of SARS-CoV-2 infection detailed in this material, there are arguments that make the prophylactic administration of Memantine and Amantadine appropriate. Memantine can provide protection for olfactory neurocircuits, decrease the aggressiveness of NMDA receptor hyperactivity, alveolar protection, and regulate cytokine mechanisms. Amantadine can alleviate viral myalgias and may be indicated in those who do not differentiate odor by dopamine deficiency. Future studies are needed to confirm or infirm the antiviral properties of the two psychotropic drugs in the SARS-CoV-2 virus. In terms of patient safety, Memantine is considered the NMDA inhibitor with the best clinical tolerance. The recognized action of Amantadine in influenza infection correlated with the antiviral effects of Memantine could be an argument for the association of Amantadine with Memantine, which may have a reciprocal potentiation for antiviral prophylaxis simultaneously with the control of neurological and psychiatric symptoms in patients with SMI.

\section{Conflict of interests}

The authors declare that they have no conflict of interests.

\section{Acknowledgments}

This paper was written in memory of Academician Nicolae Cajal (1919-2004), an outstanding personality of world virology.

\section{References}

[1] National Institute of Mental Health (NIMH). Mental illness. Mental Health Information, Statistics, last updated: January 2021. https://www.nimh.nih.gov/health/statistics/mental-illness. shtml

[2] National Mental Health Intelligence Network with particular input from Lachowycz K, Celebi S, Price G, Lugton C, Roche R. 
Research and analysis. Severe mental illness (SMI) and physical health inequalities: briefing. Public Health England, Mental Health, 27 September 2018. https://www.gov.uk/ government/publications/severe-mental-illness-smi-physicalhealth-inequalities/severe-mental-illness-and-physical-healthinequalities-briefing\#smi-prevalence

[3] Goff DC, Cather C, Evins AE, Henderson DC, Freudenreich O, Copeland PM, Bierer M, Duckworth K, Sacks FM. Medical morbidity and mortality in schizophrenia: guidelines for psychiatrists. J Clin Psychiatry, 2005, 66(2):183-194; quiz 147, 273-274. https://doi.org/10.4088/jcp.v66n0205 PMID: 15705003

[4] Sokal J, Messias E, Dickerson FB, Kreyenbuhl J, Brown CH, Goldberg RW, Dixon LB. Comorbidity of medical illnesses among adults with serious mental illness who are receiving community psychiatric services. J Nerv Ment Dis, 2004, 192(6): 421-427. https://doi.org/10.1097/01.nmd.0000130135.78017. 96 PMID: 15167405

[5] Frankiewicz T, Potier B, Bashir ZI, Collingridge GL, Parsons CG Effects of memantine and MK-801 on NMDA-induced currents in cultured neurones and on synaptic transmission and LTP in area CA1 of rat hippocampal slices. Br J Pharmacol, 1996, 117(4):689-697. https://doi.org/10.1111/j.1476-5381.1996.tb 15245.x PMID: 8646415 PMCID: PMC1909336

[6] Rammes G, Danysz W, Parsons CG. Pharmacodynamics of memantine: an update. Curr Neuropharmacol, 2008, 6(1): 55-78. https://doi.org/10.2174/157015908783769671 PMID: 19305788 PMCID: PMC2645549

[7] Seeman P, Caruso C, Lasaga M. Memantine agonist action at dopamine D2 ${ }^{\text {High }}$ receptors. Synapse, 2008, 62(2):149-153. https://doi.org/10.1002/syn.20472 PMID: 18000814

[8] de Roin S, Winters S. Amantadine hydrochloride: current and new uses. J Neurosci Nurs, 1990, 22(5):322-325. https:// doi.org/10.1097/01376517-199010000-00011 PMID: 2146341

[9] Nisar T, Sutherland-Foggio H, Husar W. Antiviral amantadine. Lancet Neurol, 2019, 18(12):1080. https://doi.org/10.1016/ S1474-4422(19)30361-8 PMID: 31973807

[10] Keppel Hesselink JM. Amantadine and phenytoin: patent protected cases of drug repositioning. Clin Invest (Lond), 2017, 7(1):11-16. https://doi.org/10.4172/Clinical-Investigation.100 0105

[11] Limphaibool N, Iwanowski P, Holstad MJV, Kobylarek D, Kozubski W. Infectious etiologies of parkinsonism: pathomechanisms and clinical implications. Front Neurol, 2019, 10:652. https://doi.org/10.3389/fneur.2019.00652 PMID: 31275235 PMCID: PMC6593078

[12] Itzhaki RF, Lathe R, Balin BJ, Ball MJ, Bearer EL, Braak H, Bullido MJ, Carter C, Clerici M, Cosby SL, Del Tredici K, Field H, Fulop T, Grassi C, Griffin WS, Haas J, Hudson AP, Kamer AR, Kell DB, Licastro F, Letenneur L, Lövheim $H$, Mancuso R, Miklossy J, Otth C, Palamara AT, Perry G, Preston C, Pretorius E, Strandberg T, Tabet N, TaylorRobinson SD, Whittum-Hudson JA. Microbes and Alzheimer's disease. J Alzheimers Dis, 2016, 51(4):979-984. https:// doi.org/10.3233/JAD-160152 PMID: 26967229 PMCID: PMC5457904

[13] Desforges M, Le Coupanec A, Brison E, Meessen-Pinard M, Talbot PJ. Neuroinvasive and neurotropic human respiratory coronaviruses: potential neurovirulent agents in humans. Adv Exp Med Biol, 2014, 807:75-96. https://doi.org/10.1007/97881-322-1777-0 6 PMID: 24619619 PMCID: PMC7121612

[14] Desforges M, Le Coupanec A, Dubeau P, Bourgouin A, Lajoie L, Dubé M, Talbot PJ. Human coronaviruses and other respiratory viruses: underestimated opportunistic pathogens of the central nervous system? Viruses, 2019, 12(1):14. https:// doi.org/10.3390/v12010014 PMID: 31861926 PMCID: PMC 7020001

[15] Netland J, Meyerholz DK, Moore S, Cassell M, Perlman S. Severe acute respiratory syndrome coronavirus infection causes neuronal death in the absence of encephalitis in mice transgenic for human ACE2. J Virol, 2008, 82(15):72647275. https://doi.org/10.1128/JVI.00737-08 PMID: 18495771 PMCID: PMC2493326

[16] Arbour N, Day R, Newcombe J, Talbot PJ. Neuroinvasion by human respiratory coronaviruses. J Virol, 2000, 74(19):89138921. https://doi.org/10.1128/jvi.74.19.8913-8921.2000 PMID: 10982334 PMCID: PMC102086
[17] Brison E, Jacomy $H$, Desforges M, Talbot PJ. Novel treatment with neuroprotective and antiviral properties against a neuroinvasive human respiratory virus. J Virol, 2014, 88(3):15481563. https://doi.org/10.1128/JVI.02972-13 PMID: 24227863 PMCID: PMC3911624

[18] Devanand DP. Viral hypothesis and antiviral treatment in Alzheimer's disease. Curr Neurol Neurosci Rep, 2018, 18(9): 55. https://doi.org/10.1007/s11910-018-0863-1 PMID: 30008124 PMCID: PMC6450072

[19] Devanand DP, Andrews H, Kreisl WC, Razlighi Q, Gershon A Stern Y, Mintz A, Wisniewski T, Acosta E, Pollina J, Katsikoumbas $M$, Bell KL, Pelton $G H$, Deliyannides $D$, Prasad KM, Huey ED. Antiviral therapy: Valacyclovir treatment of Alzheimer's Disease (VALAD) trial: protocol for a randomised, double-blind, placebo-controlled, treatment trial. BMJ Open, 2020, 10(2):e032112. https://doi.org/10.1136/bmjopen-2019032112 PMID: 32034019 PMCID: PMC7045215

[20] Itzhaki RF. Herpes simplex virus type 1 and Alzheimer's disease: increasing evidence for a major role of the virus. Front Aging Neurosci, 2014, 6:202. https://doi.org/10.3389/fnagi.2014.0 0202 PMID: 25157230 PMCID: PMC4128394

[21] Sang CN, Booher S, Gilron I, Parada S, Max MB. Dextromethorphan and memantine in painful diabetic neuropathy and postherpetic neuralgia: efficacy and dose-response trials. Anesthesiology, 2002, 96(5):1053-1061. https://doi.org/10. 1097/00000542-200205000-00005 PMID: 11981142

[22] Pickering G, Morel V. Memantine for the treatment of general neuropathic pain: a narrative review. Fundam Clin Pharmacol, 2018, 32(1):4-13. https://doi.org/10.1111/fcp.12316 PMID: 28802070

[23] Ellis R, Langford D, Masliah E. HIV and antiretroviral therapy in the brain: neuronal injury and repair. Nat Rev Neurosci, 2007, 8(1):33-44. https://doi.org/10.1038/nrn2040 PMID: 17180161

[24] Calvez M, Hseeh G, Benzer S, Brown AM. Osteopontin counters human immunodeficiency virus type 1-induced impairment of neurite growth through mammalian target of rapamycin and beta-integrin signaling pathways. J Neurovirol, 2019, 25(3):384-396. https://doi.org/10.1007/s13365-019-0 0729-y PMID: 30758811 PMCID: PMC6647884

[25] Zhu N, Zhang D, Wang W, Li X, Yang B, Song J, Zhao X, Huang B, Shi W, Lu R, Niu P, Zhan F, Ma X, Wang D, Xu W, Wu G, Gao GF, Tan W; China Novel Coronavirus Investigating and Research Team. A novel coronavirus from patients with pneumonia in China, 2019. N Engl J Med, 2020, 382(8):727733. https://doi.org/10.1056/NEJMoa2001017 PMID: 31978945 PMCID: PMC7092803

[26] Nath A, Haughey NJ, Jones M, Anderson C, Bell JE, Geiger JD. Synergistic neurotoxicity by human immunodeficiency virus proteins Tat and gp120: protection by memantine. Ann Neurol, 2000, 47(2):186-194. PMID: 10665489

[27] Gemignani A, Paudice P, Pittaluga A, Raiteri M. The HIV-1 coat protein gp120 and some of its fragments potently activate native cerebral NMDA receptors mediating neuropeptide release. Eur J Neurosci, 2000, 12(8):2839-2846. https://doi.org/10. 1046/j.1460-9568.2000.00172.x PMID: 10971626

[28] Merino JJ, Montes ML, Blanco A, Bustos MJ, OrejaGuevara C, Bayon C, Cuadrado A, Lubrini G, Cambron I, Munoz A, Cebolla S, Gutierrez-Fernandez M, Bernardino JI, Arribas JR, Fiala M. [HIV-1 neuropathogenesis: therapeutic strategies against neuronal loss induced by gp120/Tat glycoprotein in the central nervous system]. Rev Neurol, 2011, 52(2):101-111. PMID: 21271550

[29] Chen W, Tang Z, Fortina P, Patel P, Addya S, Surrey S, Acheampong EA, Mukhtar M, Pomerantz RJ. Ethanol potentiates HIV-1 gp120-induced apoptosis in human neurons via both the death receptor and NMDA receptor pathways. Virology, 2005, 334(1):59-73. https://doi.org/10.1016/j.virol.2005.01.014 PMID: 15749123

[30] Shin AH, Kim HJ, Thayer SA. Subtype selective NMDA receptor antagonists induce recovery of synapses lost following exposure to HIV-1 Tat. Br J Pharmacol, 2012, 166(3):10021017. https://doi.org/10.1111/j.1476-5381.2011.01805.x PMID: 22142193 PMCID: PMC3417425

[31] Zhao Y, Navia BA, Marra CM, Singer EJ, Chang L, Berger J, Ellis RJ, Kolson DL, Simpson D, Miller EN, Lipton SA, Evans SR, Schifitto G; Adult Aids Clinical Trial Group (ACTG) 301 Team. Memantine for AIDS dementia complex: open-label report of 
ACTG 301. HIV Clin Trials, 2010, 11(1):59-67. https://doi.org/ 10.1310/hct1101-59 PMID: 20400412 PMCID: PMC2981797

[32] Mercorelli $B$, Palù $G$, Loregian A. Drug repurposing for viral infectious diseases: how far are we? Trends Microbiol, 2018 26(10):865-876. https://doi.org/10.1016/j.tim.2018.04.004 PMID: 29759926 PMCID: PMC7126639

[33] Bule M, Khan F, Niaz K. Antivirals: past, present and future. In: Malik YS, Singh RK, Yadav MP (eds). Recent advances in animal virology. Springer Nature, Singapore, 2019, 425446. https://doi.org/10.1007/978-981-13-9073-9 22 PMCID: PMC7120554

[34] Sirohi D, Kuhn RJ. Can an FDA-approved Alzheimer's drug be repurposed for alleviating neuronal symptoms of Zika virus? mBio, 2017, 8(3):e00916-17. https://doi.org/10.1128/mBio.0 0916-17 PMID: 28655823 PMCID: PMC5487734

[35] Costa VV, Del Sarto JL, Rocha RF, Silva FR, Doria JG, Olmo IG, Marques RE, Queiroz-Junior CM, Foureaux G, Araújo JMS, Cramer A, Real ALCV, Ribeiro LS, Sardi SI, Ferreira AJ, Machado FS, de Oliveira AC, Teixeira AL, Nakaya HI, Souza DG, Ribeiro FM, Teixeira MM. N-methyld-aspartate (NMDA) receptor blockade prevents neuronal death induced by Zika virus infection. mBio, 2017, 8(2):e00350-17. https://doi.org/10.1128/mBio.00350-17 PMID: 28442607 PMCID: PMC5405231

[36] Staničová J, Miškovský P, Šutiak V, Amantadine: an antiviral and antiparkinsonian agent. Vet Med, 2001, 46(9-10):244256. https://doi.org/10.17221/7884-VETMED

[37] Tamblyn SE. Amantadine use in influenza outbreaks in longterm care facilities. CMAJ, 1997, 157(11):1573-1576. PMID: 9400415 PMCID: PMC1228575

[38] Stiver G. The treatment of influenza with antiviral drugs. CMAJ, 2003, 168(1):49-56. PMID: 12515786 PMCID: PMC139319

[39] Vanle B, Olcott W, Jimenez J, Bashmi L, Danovitch I, Ishak WW. NMDA antagonists for treating the non-motor symptoms in Parkinson's disease. Transl Psychiatry, 2018, 8(1):117. https:// doi.org/10.1038/s41398-018-0162-2 PMID: 29907742 PMCID: PMC6003962

[40] Stubendorff K, Larsson V, Ballard C, Minthon L, Aarsland D, Londos E. Treatment effect of memantine on survival in dementia with Lewy bodies and Parkinson's disease with dementia: a prospective study. BMJ Open, 2014, 4:e005158. https://doi.org/10.1136/bmjopen-2014-005158 PMID: 24993765 PMCID: PMC4091277

[41] Fazzini E, Fleming J, Fahn S. Cerebrospinal fluid antibodies to coronavirus in patients with Parkinson's disease. Mov Disord, 1992, 7(2):153-158. https://doi.org/10.1002/mds.870070210 PMID: 1316552 PMCID: PMC7168426

[42] Huang C, Wang Y, Li X, Ren L, Zhao J, Hu Y, Zhang L, Fan G, Xu J, Gu X, Cheng Z, Yu T, Xia J, Wei Y, Wu W, Xie X, Yin W, Li H, Liu M, Xiao Y, Gao H, Guo L, Xie J, Wang G, Jiang R, Gao Z, Jin Q, Wang J, Cao B. Clinical features of patients infected with 2019 novel coronavirus in Wuhan, China. Lancet, 2020, 395(10223):497-506. https://doi.org/10.1016/S01406736(20)30183-5 PMID: 31986264 PMCID: PMC7159299

[43] Zhang Y, Xiao M, Zhang S, Xia P, Cao W, Jiang W, Chen H, Ding $X$, Zhao $\mathrm{H}$, Zhang $\mathrm{H}$, Wang $\mathrm{C}$, Zhao J, Sun $\mathrm{X}$, Tian $\mathrm{R}$, Wu W, Wu D, Ma J, Chen Y, Zhang D, Xie J, Yan X, Zhou X, Liu Z, Wang J, Du B, Qin Y, Gao P, Qin X, Xu Y, Zhang W, Li T, Zhang F, Zhao Y, Li Y, Zhang S. Coagulopathy and antiphospholipid antibodies in patients with Covid-19. N Engl J Med, 2020, 382(17):e38. https://doi.org/10.1056/NEJMc20 07575 PMID: 32268022 PMCID: PMC7161262

[44] Spyropoulos AC, Ageno W, Barnathan ES. Hospital-based use of thromboprophylaxis in patients with COVID-19. Lancet 2020, 395(10234):e75. https://doi.org/10.1016/S0140-6736 (20)30926-0 PMID: 32330428 PMCID: PMC7173816

[45] Chan MCW, Cheung CY, Chui WH, Tsao SW, Nicholls JM, Chan YO, Chan RWY, Long HT, Poon LLM, Guan Y, Peiris JSM Proinflammatory cytokine responses induced by influenza A (H5N1) viruses in primary human alveolar and bronchial epithelial cells. Respir Res, 2005, 6(1):135. https://doi.org/ 10.1186/1465-9921-6-135 PMID: 16283933 PMCID: PMC 1318487

[46] Jiang Y, Xu J, Zhou C, Wu Z, Zhong S, Liu J, Luo W, Chen T, Qin Q, Deng P. Characterization of cytokine/chemokine profiles of severe acute respiratory syndrome. Am J Respir Crit Care Med, 2005, 171(8):850-857. https://doi.org/10.1164/rccm.2 00407-857OC PMID: 15657466
[47] Zheng YY, Ma YT, Zhang JY, Xie X. COVID-19 and the cardiovascular system. Nat Rev Cardiol, 2020, 17(5):259-260. https://doi.org/10.1038/s41569-020-0360-5 PMID: 32139904 PMCID: PMC7095524

[48] Baig AM. Updates on what ACS reported: emerging evidences of COVID-19 with nervous system involvement. ACS Chem Neurosci, 2020, 11(9):1204-1205. https://doi.org/10.1021/ acschemneuro.0c00181 PMID: 32343122 PMCID: PMC 7192204

[49] Asadi-Pooya AA. Seizures associated with coronavirus infections Seizure, 2020, 79:49-52. https://doi.org/10.1016/j.seizure.2 020.05.005 PMID: 32416567 PMCID: PMC7212943

[50] Iori V, Frigerio F, Vezzani A. Modulation of neuronal excitability by immune mediators in epilepsy. Curr Opin Pharmacol, 2016, 26:118-123. https://doi.org/10.1016/j.coph.2015.11.002 PMID: 26629681 PMCID: PMC4716878

[51] Galic MA, Riazi K, Pittman QJ. Cytokines and brain excitability. Front Neuroendocrinol, 2012, 33(1):116-125. https://doi.org/ 10.1016/j.yfrne.2011.12.002 PMID: 22214786 PMCID: PMC 3547977

[52] Mao L, Jin H, Wang M, Hu Y, Chen S, He Q, Chang J, Hong C, Zhou Y, Wang D, Miao X, Li Y, Hu B. Neurologic manifestations of hospitalized patients with coronavirus disease 2019 in Wuhan, China. JAMA Neurol, 2020, 77(6):683-690. https://doi.org/10.1001/jamaneurol.2020.1127 PMID: 32275288 PMCID: PMC7149362

[53] Li YC, Bai WZ, Hashikawa T. The neuroinvasive potential of SARS-CoV2 may play a role in the respiratory failure of COVID-19 patients. J Med Virol, 2020, 92(6):552-555. https:// doi.org/10.1002/jmv.25728 PMID: 32104915 PMCID: PMC 7228394

[54] Braak H, Del Tredici K, Rüb U, de Vos RAl, Jansen Steur $\mathrm{ENH}$, Braak E. Staging of brain pathology related to sporadic Parkinson's disease. Neurobiol Aging, 2003, 24(2):197211. https://doi.org/10.1016/s0197-4580(02)00065-9 PMID: 12498954

[55] Chen Z, Li G, Liu J. Autonomic dysfunction in Parkinson's disease: implications for pathophysiology, diagnosis, and treatment. Neurobiol Dis, 2020, 134:104700. https://doi.org/ 10.1016/j.nbd.2019.104700 PMID: 31809788

[56] Baryah ANS, Midha V, Mahajan R, Sood A. Impact of corona virus disease-19 (COVID-19) pandemic on gastrointestinal disorders. Indian J Gastroenterol, 2020, 39(3):214-219. https://doi.org/10.1007/s12664-020-01071-6

[57] Wong SH, Lui RN, Sung JJ. Covid-19 and the digestive system. J Gastroenterol Hepatol, 2020, 35(5):744-748. https://doi.org/ 10.1111/jgh.15047 PMID: 32215956

[58] Ziemssen T, Reichmann H. Treatment of dysautonomia in extrapyramidal disorders. Ther Adv Neurol Disord, 2010, 3(1):53-67. https://doi.org/10.1177/1756285609348902 PMID: 21180636 PMCID: PMC3002611

[59] Mulkey SB, du Plessis AJ. Autonomic nervous system development and its impact on neuropsychiatric outcome. Pediatr Res, 2019, 85(2):120-126. https://doi.org/10.1038/ s41390-018-0155-0 PMID: 30166644 PMCID: PMC6353676

[60] Quan W, Wang Y, Chen S, Du J. Orthostatic intolerance and coagulation abnormalities: an update. Neurosci Bull, 2019, 35(1):171-177. https://doi.org/10.1007/s12264-018-0295-6 PMID: 30315398 PMCID: PMC6357271

[61] Kraemer M, Kuepper M, Nebe-vom Stein A, Sorgenfrei U, Diehl RR. The influence of vasovagal response on the coagulation system. Clin Auton Res, 2010, 20(2):105-111. https://doi.org/10.1007/s10286-009-0022-5 PMID: 19633908

[62] Isma N, Sutton R, Hillarp A, Strandberg K, Melander O, Fedorowski A. Higher levels of von Willebrand factor in patients with syncope due to orthostatic hypotension. J Hypertens, 2015, 33(8):1594-1601. https://doi.org/10.1097/HJH.00000 00000000595 PMID: 26136066

[63] Masoud M, Sarig G, Brenner B, Jacob G. Orthostatic hypercoagulability: a novel physiological mechanism to activate the coagulation system. Hypertension, 2008, 51(6):15451551. https://doi.org/10.1161/HYPERTENSIONAHA.108.11 2003 PMID: 18413485

[64] Bayer AU, Keller ON, Ferrari F, Maag KP. Association of glaucoma with neurodegenerative diseases with apoptotic cell death: Alzheimer's disease and Parkinson's disease. Am J Ophthalmol, 2002, 133(1):135-137. https://doi.org/10.1016/ s0002-9394(01)01196-5 PMID: 11755850 
[65] Ekker MS, Janssen S, Seppi K, Poewe W, de Vries NM Theelen T, Nonnekes J, Bloem BR. Ocular and visual disorders in Parkinson's disease: common but frequently overlooked. Parkinsonism Relat Disord, 2017, 40:1-10. https://doi.org/ 10.1016/j.parkreldis.2017.02.014 PMID: 28284903

[66] Park HYL, Jung SH, Park SH, Park CK. Detecting autonomic dysfunction in patients with glaucoma using dynamic pupillometry. Medicine (Baltimore), 2019, 98(11):e14658. https://doi.org/ 10.1097/MD.0000000000014658 PMID: 30882629 PMCID: PMC6426567

[67] Moog P, Eren O, Witt M, Rauschel V, Kossegg S, Straube A Grünke M, Schulze-Koops H. Assessment of autonomic function in a cohort of patients with ANCA-associated vasculitis. Clin Auton Res, 2016, 26(4):279-285. https://doi.org/10.1007/ s10286-016-0364-8 PMID: 27364144

[68] Manno RL, Seo P, Geetha D. Older patients with ANCAassociated vasculitis and dialysis dependent renal failure: a retrospective study. BMC Nephrol, 2015, 16:88. https://doi.org/ 10.1186/s12882-015-0082-9 PMID: 26108549 PMCID: PMC 4481069

[69] Sühs KW, Fairless R, Williams SK, Heine K, Cavalié A, Diem R. N-methyl-D-aspartate receptor blockade is neuroprotective in experimental autoimmune optic neuritis. J Neuropathol Exp Neurol, 2014, 73(6):507-518. https://doi.org/10. 1097/NEN.0000000000000073 PMID: 24806299

[70] Wu HM, Tzeng NS, Qian L, Wei SJ, Hu X, Chen SH, Rawls SM, Flood P, Hong JS, Lu RB. Novel neuroprotective mechanisms of memantine: increase in neurotrophic factor release from astroglia and anti-inflammation by preventing microglial activation. Neuropsychopharmacology, 2009, 34(10): 2344-2357. https://doi.org/10.1038/npp.2009.64 PMID: 19536110 PMCID: PMC3655438

[71] Hughes PM, Olejnik O. Memantine delivery to the back of the eye. United States Patent Application Publication, Pub. No. US 2005/0277698 A1, 2005, December 15. https://patent images.storage.googleapis.com/63/01/43/5b7e45535659fb/ US20050277698A1.pdf

[72] Hare WA, WoldeMussie E, Weinreb RN, Ton H, Ruiz G Wijono M, Feldmann B, Zangwill L, Wheeler L. Efficacy and safety of memantine treatment for reduction of changes associated with experimental glaucoma in monkey, II: Structural measures. Invest Ophthalmol Vis Sci, 2004, 45(8):2640-2651. https://doi.org/10.1167/iovs.03-0567 PMID: 15277487

[73] Maciulaitiene R, Pakuliene G, Kaja S, Pauza DH, Kalesnykas G Januleviciene I. Glioprotection of retinal astrocytes after intravitreal administration of memantine in the mouse optic nerve crush model. Med Sci Monit, 2017, 23:1173-1179. https://doi.org/10.12659/msm.899699 PMID: 28265105 PMCID: PMC5352005

[74] Richa S, Yazbek JC. Ocular adverse effects of common psychotropic agents: a review. CNS Drugs, 2010, 24(6): 501-526. https://doi.org/10.2165/11533180-000000000-00000 PMID: 20443647

[75] Boonyaleephan S. Drug-induced secondary glaucoma. J Med Assoc Thai, 2010, 93(Suppl 2):S118-S122. PMID: 21299086

76] Recla JM, Sarantopoulos CD. Combined use of pregabalin and memantine in fibromyalgia syndrome treatment: a novel analgesic and neuroprotective strategy? Med Hypotheses, 2009, 73(2):177-183. https://doi.org/10.1016/j.mehy.2009.01. 052 PMID: 19362430 PMCID: PMC2739678

[77] Zhou HY, Chen SR, Pan HL. Targeting N-methyl-D-aspartate receptors for treatment of neuropathic pain. Expert Rev Clin Pharmacol, 2011, 4(3):379-388. https://doi.org/10.1586/ecp. 11.17 PMID: 21686074 PMCID: PMC3113704

[78] Loix S, De Kock M, Henin P. The anti-inflammatory effects of ketamine: state of the art. Acta Anaesthesiol Belg, 2011, 62(1):47-58. PMID: 21612145

[79] Johnson JW, Glasgow NG, Povysheva NV. Recent insights into the mode of action of memantine and ketamine. Curr Opin Pharmacol, 2015, 20:54-63. https://doi.org/10.1016/j. coph.2014.11.006 PMID: 25462293 PMCID: PMC4318755

[80] Fisher K, Coderre TJ, Hagen NA. Targeting the N-methyl-Daspartate receptor for chronic pain management. Preclinical animal studies, recent clinical experience and future research directions. J Pain Symptom Manage, 2000, 20(5):358-373. https://doi.org/10.1016/s0885-3924(00)00213-x PMID: 11068158

[81] Gilligan DM, Chan WL, Sbarouni E, Nihoyannopoulos P Oakley CM. Autonomic function in hypertrophic cardiomyopathy.
Br Heart J, 1993, 69(6):525-529. https://doi.org/10.1136/ hrt.69.6.525 PMID: 8343320 PMCID: PMC1025165

[82] Glaveckaitè $S$, Šerpytis $P$, Pečiūraitè $D$, Puronaitè R, Valevičienè N. Clinical features and three-year outcomes of Takotsubo (stress) cardiomyopathy: observational data from one center. Hellenic J Cardiol, 2016, 57(6):428-434. https:// doi.org/10.1016/j.hjc.2016.11.016 PMID: 28087310

[83] Katagiri A, Asahina M, Araki N, Poudel A, Fujinuma Y Yamanaka Y, Kuwabara S. Myocardial ${ }^{123}$ I-MIBG uptake and cardiovascular autonomic function in Parkinson's disease. Parkinsons Dis, 2015, 2015:805351. https://doi.org/10.1155/ 2015/805351 PMID: 26649224 PMCID: PMC4663005

[84] Sakakibara R, Tateno F, Kishi M, Tsuyusaki $Y$, Terada H, Inaoka T. MIBG myocardial scintigraphy in pre-motor Parkinson's disease: a review. Parkinsonism Relat Disord, 2014, 20(3): 267-273. https://doi.org/10.1016/j.parkreldis.2013.11.001 PMID: 24332912

[85] Kawazoe M, Arima H, Maeda T, Tsuji M, Mishima T, Fujioka S, Tsugawa J, Tsuboi Y. Sensitivity and specificity of cardiac ${ }^{123}$ I-MIBG scintigraphy for diagnosis of early-phase Parkinson's disease. J Neurol Sci, 2019, 407:116409. https://doi.org/10. 1016/j.jns.2019.07.027 PMID: 31706063

[86] Shill H, Stacy M. Respiratory complications of Parkinson's disease. Semin Respir Crit Care Med, 2002, 23(3):261-265. https://doi.org/10.1055/s-2002-33034 PMID: 16088618

[87] O'Callaghan A, Walker R. A review of pulmonary function in Parkinson's disease. J Parkinsonism Restless Leg Syndr, 2018, 8:13-23. https://doi.org/10.2147/JPRLS.S114309

[88] Scorza FA, do Carmo AC, Fiorini AC, Nejm MB, Scorza CA Finsterer J, Ferraz HB. Sudden unexpected death in Parkinson's disease (SUDPAR): a review of publications since the decade of the brain. Clinics (Sao Paulo), 2017, 72(11):649-651. https://doi.org/10.6061/clinics/2017(11)01 PMID: 29236909 PMCID: PMC5706063

[89] McGee MA, Abdel-Rahman AA. N-methyl-D-aspartate receptor signaling and function in cardiovascular tissues. J Cardiovasc Pharmacol, 2016, 68(2):97-105. https://doi.org/10.1097/FJC. 0000000000000398 PMID: 27046337 PMCID: PMC4980173

[90] Lewis SJ, Barres C, Jacob HJ, Ohta H, Brody MJ. Cardiovascular effects of the $\mathrm{N}$-methyl-D-aspartate receptor antagonist MK-801 in conscious rats. Hypertension, 1989, 13(6 Pt 2):759765. https://doi.org/10.1161/01.hyp.13.6.759 PMID: 2544522

[91] Abbaszadeh S, Javidmehr A, Askari B, Janssen PML, Soraya H. Memantine, an NMDA receptor antagonist, attenuates cardiac remodeling, lipid peroxidation and neutrophil recruitment in heart failure: a cardioprotective agent? Biomed Pharmacother, 2018, 108:1237-1243. https://doi.org/10.1016/j.biopha.2018. 09.153 PMID: 30372825

[92] Escanilla O, Yuhas C, Marzan D, Linster C. Dopaminergic modulation of olfactory bulb processing affects odor discrimination learning in rats. Behav Neurosci, 2009, 123(4):828-833. https://doi.org/10.1037/a0015855 PMID: 19634942 PMCID: PMC2766664

[93] Stovicek PO, Friedmann C, Marinescu D, Văduva IA, Bondari S, Trifu SC, Marinescu I. Mild TBI in the elderly - risk factor for rapid cognitive impairment in Alzheimer's disease. Rom $\mathrm{J}$ Morphol Embryol, 2020, 61(1):61-72. https://doi.org/10.47162/ RJME.61.1.07 PMID: 32747896 PMCID: PMC7728108

[94] Yehuda S, Rabinovitz S. Olfactory bulbectomy as a putative model for Alzheimer': the protective role of essential fatty acids. PharmaNutrition, 2014, 2(1):12-18. https://doi.org/10. 1016/j.phanu.2013.10.002

[95] Borre Y, Bosman E, Lemstra S, Westphal KG, Oosting RS. Memantine partly rescues behavioral and cognitive deficits in an animal model of neurodegeneration. Neuropharmacology, 2012, 62(5-6):2010-2017. https://doi.org/10.1016/j.neuropharm. 2011.12.034 PMID: 22248638

[96] Wright JW, Kawas LH, Harding JW. A role for the brain RAS in Alzheimer's and Parkinson's diseases. Front Endocrinol (Lausanne), 2013, 4:158. https://doi.org/10.3389/fendo.2013. 00158 PMID: 24298267 PMCID: PMC3829467

[97] Wang G, Coleman CG, Chan J, Faraco G, Marques-Lopes J, Milner TA, Guruju MR, Anrather J, Davisson RL, ladecola C, Pickel VM. Angiotensin II slow-pressor hypertension enhances NMDA currents and NOX2-dependent superoxide production in hypothalamic paraventricular neurons. Am J Physiol Regul Integr Comp Physiol, 2013, 304(12):R1096-R1106. https:// doi.org/10.1152/ajpregu.00367.2012 PMID: 23576605 PMCID: PMC3680791 
[98] Simon SA, de Araujo IE, Gutierrez R, Nicolelis MAL. The neural mechanisms of gustation: a distributed processing code. Nat Rev Neurosci, 2006, 7(11):890-901. https://doi.org/10.1038/ nrn2006 PMID: 17053812

[99] Montalvan V, Lee J, Bueso T, De Toledo J, Rivas K. Neurological manifestations of COVID-19 and other coronavirus infections: a systematic review. Clin Neurol Neurosurg, 2020, 194:105921. https://doi.org/10.1016/j.clineuro.2020.105921 PMID: 32422545 PMCID: PMC7227498

[100] Yoritaka A, Ohizumi H, Tanaka S, Hattori N. Parkinson's disease with and without REM sleep behaviour disorder: are there any clinical differences? Eur Neurol, 2009, 61(3): 164-170. https://doi.org/10.1159/000189269 PMID: 19129703

[101] Zhou J, Zhang J, Lam SP, Mok V, Chan A, Li SX, Liu Y, Tang $X$, Yung WH, Wing YK. Mortality and its risk factors in patients with rapid eye movement sleep behavior disorder. Sleep, 2016, 39(8):1543-1550. https://doi.org/10.5665/sleep. 6016 PMID: 27306273 PMCID: PMC4945313

[102] Thijs RD. The autonomic signatures of epilepsy: diagnostic clues and novel treatment avenues. Clin Auton Res, 2019, 29(2):131-133. https://doi.org/10.1007/s10286-019-00603-1 PMID: 30903303

[103] Roberts LN, Bramham K, Sharpe CC, Arya R. Hypercoagulability and anticoagulation in patients with COVID19 requiring renal replacement therapy. Kidney Int Rep, 2020, 5(9):1377-1380. https://doi.org/10.1016/j.ekir.2020. 07.024 PMID: 32838085 PMCID: PMC7381908

[104] Ridker PM. Anticytokine agents: targeting interleukin signaling pathways for the treatment of atherothrombosis. Circ Res, 2019, 124(3):437-450. https://doi.org/10.1161/CIRCRESA HA.118.313129 PMID: 30702995 PMCID: PMC6386195

[105] Tuñón J, Martín-Ventura JL, Blanco-Colio LM, Tarín N, Egido J. Common pathways of hypercholesterolemia and hypertension leading to atherothrombosis: the need for a global approach in the management of cardiovascular risk factors. Vasc Health Risk Manag, 2007, 3(4):521-526. PMID: 17969382 PMCID: PMC2291342

[106] Shi W, Lv J, Lin L. Coagulopathy in COVID-19: focus on vascular thrombotic events. J Mol Cell Cardiol, 2020, 146: 32-40. https://doi.org/10.1016/j.yjmcc.2020.07.003 PMID: 32681845 PMCID: PMC7362808

[107] Ragab D, Salah Eldin H, Taeimah M, Khattab R, Salem R. The COVID-19 cytokine storm; what we know so far. Front Immunol, 2020, 11:1446. https://doi.org/10.3389/fimmu. 2020.01446 PMID: 32612617 PMCID: PMC7308649

[108] Castelli V, Cimini A, Ferri C. Cytokine storm in COVID-19: "when you come out of the storm, you won't be the same person who walked in". Front Immunol, 2020, 11:2132. https://doi.org/10.3389/fimmu.2020.02132 PMID: 32983172 PMCID: PMC7492381

[109] Lee SY, Chen SL, Chang YH, Chen PS, Huang SY, Tzeng NS, Wang YS, Wang LJ, Lee IH, Wang TY, Yeh TL, Yang YK, Hong JS, Lu RB. The effects of add-on low-dose memantine on cytokine levels in bipolar II depression: a 12-week double-blind, randomized controlled trial. J Clin Psychopharmacol, 2014, 34(3):337-343. https://doi.org/10. 1097/JCP.0000000000000109 PMID: 24717258

[110] Miller AH, Haroon E, Raison CL, Felger JC. Cytokine targets in the brain: impact on neurotransmitters and neurocircuits. Depress Anxiety, 2013, 30(4):297-306. https://doi.org/10. 1002/da.22084 PMID: 23468190 PMCID: PMC4141874

[111] Haroon E, Miller AH, Sanacora G. Inflammation, glutamate, and glia: a trio of trouble in mood disorders. Neuropsychopharmacology, 2017, 42(1):193-215. https://doi.org/10.10 38/npp.2016.199 PMID: 27629368 PMCID: PMC5143501

[112] Bansal S, Singh S, Sharma A. Role of reactive oxygen species (ROS) and cytokines in vascular dementia: a review. Int J Pharm Teach Pract, 2015, 6(4):2620-2629. https:// www.iomcworld.org/abstract/role-of-reactive-oxygen-speciesros-and-cytokines-in-vascular-dementia-a-review-25820.html

[113] Kamat PK, Tota S, Rai S, Swarnkar S, Shukla R, Nath C. A study on neuroinflammatory marker in brain areas of okadaic acid (ICV) induced memory impaired rats. Life Sci, 2012, 90(19-20):713-720. https://doi.org/10.1016/j.Ifs.2012. 03.012 PMID: 22480513

[114] Kamat PK, Tota S, Saxena G, Shukla R, Nath C. Okadaic acid (ICV) induced memory impairment in rats: a suitable experimental model to test anti-dementia activity. Brain Res, 2010, 1309:66-74. https://doi.org/10.1016/j.brainres.2009. 10.064 PMID: 19883632

[115] Huang CY, Wang LC, Shan YS, Pan CH, Tsai KJ. Memantine attenuates delayed vasospasm after experimental subarachnoid hemorrhage via modulating endothelial nitric oxide synthase. Int J Mol Sci, 2015, 16(6):14171-14180. https:// doi.org/10.3390/ijms160614171 PMID: 26110388 PMCID: PMC4490546

[116] Förstermann U, Sessa WC. Nitric oxide synthases: regulation and function. Eur Heart J, 2012, 33(7):829-837, 837a-837d. https://doi.org/10.1093/eurheartj/ehr304 PMID: 21890489 PMCID: PMC3345541

[117] Wang Y, Tang Z, Huang H, Li J, Wang Z, Yu Y, Zhang C, Li J, Dai H, Wang F, Cai T, Tang N. Pulmonary alveolar type I cell population consists of two distinct subtypes that differ in cell fate. Proc Natl Acad Sci U S A, 2018, 115(10): 2407-2412. https://doi.org/10.1073/pnas.1719474115 PMID: 29463737 PMCID: PMC5877944

[118] Mason RJ. Biology of alveolar type II cells. Respirology, 2006, 11(Suppl):S12-S15. https://doi.org/10.1111/j.14401843.2006.00800.x PMID: 16423262

[119] Cheng Q, Fang L, Feng D, Tang S, Yue S, Huang Y, Han J, Lan J, Liu W, Gao L, Luo Z. Memantine ameliorates pulmonary inflammation in a mice model of COPD induced by cigarette smoke combined with LPS. Biomed Pharmacother, 2019, 109:2005-2013. https://doi.org/10.1016/j.biopha.2018.11. 002 PMID: 30551456

[120] Li Y, Liu Y, Peng X, Liu W, Zhao F, Feng D, Han J, Huang Y, Luo S, Li L, Yue SJ, Cheng Q, Huang X, Luo Z. NMDA receptor antagonist attenuates bleomycin-induced acute lung injury. PLoS One, 2015, 10(5):e0125873. https://doi.org/ 10.1371/journal.pone.0125873 PMID: 25942563 PMCID: PMC4420245

[121] Tang $Y$, Le W. Differential roles of M1 and M2 microglia in neurodegenerative diseases. Mol Neurobiol, 2016, 53(2): 1181-1194. https://doi.org/10.1007/s12035-014-9070-5 PMID: 25598354

[122] Réus GZ, Fries GR, Stertz L, Badawy M, Passos IC, Barichello T, Kapczinski F, Quevedo J. The role of inflammation and microglial activation in the pathophysiology of psychiatric disorders. Neuroscience, 2015, 300:141-154. https://doi.org/10.1016/j.neuroscience.2015.05.018 PMID: 25981208

[123] Hamelin L, Lagarde J, Dorothée G, Potier MC, Corlier F, Kuhnast B, Caillé F, Dubois B, Fillon L, Chupin M, Bottlaender M, Sarazin M. Distinct dynamic profiles of microglial activation are associated with progression of Alzheimer's disease. Brain, 2018, 141(6):1855-1870. https:// doi.org/10.1093/brain/awy079 PMID: 29608645

[124] Fakhari A, Herizchi S, Goldust M, Yousefi Jafarabadi A. The efficacy of complementary use of memantine in treatment of schizophrenia with chronic course. J Am Sci, 2013, 9(10s):71-74. http://www.jofamericanscience.org/journals/ am-sci/am0910s/013_21035am0910s_71_74.pdf

[125] Zheng W, Li XH, Yang XH, Cai DB, Ungvari GS, Ng CH, Wang SB, Wang YY, Ning YP, Xiang YT. Adjunctive memantine for schizophrenia: a meta-analysis of randomized, double-blind, placebo-controlled trials. Psychol Med, 2018, 48(1):72-81. https://doi.org/10.1017/S0033291717001271 PMID: 28528597

[126] Di lorio G, Baroni G, Lorusso M, Montemitro C, Spano MC, di Giannantonio M. Efficacy of memantine in schizophrenic patients: a systematic review. J Amino Acids, 2017, 2017: 7021071. https://doi.org/10.1155/2017/7021071 PMID: 28243470 PMCID: PMC5294374

[127] Junho BT, de Oliveira VF. The role of NMDA receptor antagonists, amantadine and memantine, in schizophrenia treatment: a systematic review. Arch Clin Psychiatry (São Paulo), 2019, 46(6):165-168. https://doi.org/10.1590/010160830000000218

[128] Fakhri A, Pakseresht S, Haghdoost MR, Hekmatkhah N, Torkashvand M, Ghorbanzadeh B. Memantine enhances the effect of olanzapine in patients with schizophrenia: a randomized, placebo-controlled study. Acta Med Iran, 2016, 54(11):696-703. PMID: 28033691

[129] Goff DC, Coyle JT. The emerging role of glutamate in the pathophysiology and treatment of schizophrenia. Am J Psychiatry, 2001, 158(9):1367-1377. https://doi.org/10.1176/ appi.ajp.158.9.1367 PMID: 11532718 
[130] Dehelean L, Marinescu I, Stovicek PO, Andor M. Cardiovascular anomalies and evolutionary risk factors in schizophrenia - multifactorial approach. Rom J Morphol Embryol, 2019, 60(4):1105-1113. PMID: 32239085

[131] Tavakoli-Ardakani M, Abbaspour H, Farhadi Nasab A, Mazaheri Meibodi A, Kheradmand A. Study of the effect of memantine on negative sign in patients with schizophrenia and schizoaffective disorders. Iran J Pharm Res, 2018 17(Suppl):122-129. PMID: 29796036 PMCID: PMC5958331

[132] Bär KJ. Cardiac autonomic dysfunction in patients with schizophrenia and their healthy relatives - a small review. Front Neurol, 2015, 6:139. https://doi.org/10.3389/fneur. 2015.00139 PMID: 26157417 PMCID: PMC4478389

[133] Muench J, Hamer AM. Adverse effects of antipsychotic medications. Am Fam Physician, 2010, 81(5):617-622. PMID: 20187598

[134] Lucca JM, Madhan R, Parthasarathi G, Ram D. Identification and management of adverse effects of antipsychotics in a tertiary care teaching hospital. J Res Pharm Pract, 2014 3(2):46-50. https://doi.org/10.4103/2279-042X.137063 PMID: 25114936 PMCID: PMC4124679

[135] Lee SY, Wang TY, Chen SL, Chang YH, Chen PS, Huang SY, Tzeng NS, Wang LJ, Lee IH, Chen KC, Yang YK, Hong JS, Lu RB. Add-on memantine treatment for bipolar II disorder comorbid with alcohol dependence: a 12-week follow-up study. Alcohol Clin Exp Res, 2018, 42(6):1044-1050. https:// doi.org/10.1111/acer.13640 PMID: 29656414 PMCID: PMC6473794

[136] Serra G, Demontis F, Serra F, De Chiara L, Spoto A, Girardi P, Vidotto G, Serra G. Memantine: new prospective in bipolar disorder treatment. World J Psychiatry, 2014, 4(4) 80-90. https://doi.org/10.5498/wjp.v4.i4.80 PMID: 25540723 PMCID: PMC4274590

[137] Omranifard V, Rajabi F, Mohammadian-Sichani M, Maracy MR. The effect of add-on memantine on positive, negative and depressive symptoms of schizophrenia: a doubleblind, randomized, controlled trial. Actas Esp Psiquiatr, 2017, 45(3):108-115. PMID: 28594056

[138] Zarate CA Jr, Singh JB, Carlson PJ, Brutsche NE, Ameli R, Luckenbaugh DA, Charney DS, Manji HK. A randomized trial of an $\mathrm{N}$-methyl-D-aspartate antagonist in treatmentresistant major depression. Arch Gen Psychiatry, 2006, 63(8):856-864. https://doi.org/10.1001/archpsyc.63.8.856 PMID: 16894061

[139] Skolnick P, Popik P, Trullas R. Glutamate-based antidepressants: 20 years on. Trends Pharmacol Sci, 2009, 30(11):563-569. https://doi.org/10.1016/j.tips.2009.09.002 PMID: 19837463

[140] Corriger A, Pickering G. Ketamine and depression: a narrative review. Drug Des Devel Ther, 2019, 13:3051-3067. https:// doi.org/10.2147/DDDT.S221437 PMID: 31695324 PMCID: PMC6717708

[141] Serafini G, Howland RH, Rovedi F, Girardi P, Amore M The role of ketamine in treatment-resistant depression: a systematic review. Curr Neuropharmacol, 2014, 12(5):444461. https://doi.org/10.2174/1570159X12666140619204251 PMID: 25426012 PMCID: PMC4243034

[142] Bahr R, Lopez A, Rey JA. Intranasal Esketamine (Spravato ${ }^{\text {TM }}$ ) for use in treatment-resistant depression in conjunction with an oral antidepressant. P T, 2019, 44(6):340-375. PMID: 31160868 PMCID: PMC6534172

[143] Rosenblat JD, Mclntyre RS. Bipolar disorder and immune dysfunction: epidemiological findings, proposed pathophysiology and clinical implications. Brain Sci, 2017, 7(11):144. https://doi.org/10.3390/brainsci7110144 PMID: 29084144 PMCID: PMC5704151

[144] Felger JC, Lotrich FE. Inflammatory cytokines in depression: neurobiological mechanisms and therapeutic implications. Neuroscience, 2013, 246:199-229. https://doi.org/10.1016/ j.neuroscience.2013.04.060 PMID: 23644052 PMCID: PMC3741070

[145] Kappelmann N, Lewis G, Dantzer R, Jones PB, Khandaker GM Antidepressant activity of anti-cytokine treatment: a systematic review and meta-analysis of clinical trials of chronic inflammatory conditions. Mol Psychiatry, 2018, 23(2):335-343. https://doi.org/10.1038/mp.2016.167 PMID: 27752078 PMCID: PMC5794896
[146] Pelton GH, Harper OL, Roose SP, Marder K, D'Antonio K, Devanand DP. Combined treatment with memantine/ escitalopram for older depressed patients with cognitive impairment: a pilot study. Int J Geriatr Psychiatry, 2016, 31(6):648-655. https://doi.org/10.1002/gps.4375 PMID: 26559790

[147] Lavretsky H, Laird KT, Krause-Sorio B, Heimberg BF, Yeargin J, Grzenda A, Wu P, Thana-Udom K, Ercoli LM, Siddarth $\mathrm{P}$. A randomized double-blind placebo-controlled trial of combined escitalopram and memantine for older adults with major depression and subjective memory complaints. Am J Geriatr Psychiatry, 2020, 28(2):178-190. https://doi.org/10.1016/j.jagp.2019.08.011 PMID: 31519517 PMCID: PMC6997044

[148] Amidfar M, Khiabany M, Kohi A, Salardini E, Arbabi M, Roohi Azizi M, Zarrindast MR, Mohammadinejad P, Zeinoddini A, Akhondzadeh S. Effect of memantine combination therapy on symptoms in patients with moderateto-severe depressive disorder: randomized, double-blind, placebo-controlled study. J Clin Pharm Ther, 2017, 42(1): 44-50. https://doi.org/10.1111/jcpt.12469 PMID: 27809351

[149] Stryjer R, Strous RD, Shaked G, Bar F, Feldman B, Kotler M, Polak L, Rosenzcwaig S, Weizman A. Amantadine as augmentation therapy in the management of treatmentresistant depression. Int Clin Psychopharmacol, 2003, 18(2): 93-96. https://doi.org/10.1097/00004850-200303000-00005 PMID: 12598820

[150] Raupp-Barcaro IF, Vital MA, Galduróz JC, Andreatini R. Potential antidepressant effect of amantadine: a review of preclinical studies and clinical trials. Braz J Psychiatry, 2018, 40(4):449-458. https://doi.org/10.1590/1516-44462017-2393 PMID: 29898194 PMCID: PMC6899375

[151] Gold PW, Machado-Vieira R, Pavlatou MG. Clinical and biochemical manifestations of depression: relation to the neurobiology of stress. Neural Plast, 2015, 2015:581976. https://doi.org/10.1155/2015/581976 PMID: 25878903 PMCID: PMC4387963

[152] Vian J, Pereira C, Chavarria V, Köhler C, Stubbs B, Quevedo J, Kim SW, Carvalho AF, Berk M, Fernandes BS. The renin-angiotensin system: a possible new target for depression. BMC Med, 2017, 15(1):144. https://doi.org/ 10.1186/s12916-017-0916-3 PMID: 28760142 PMCID: PMC5537940

[153] Harris SA, Harris EA. Molecular mechanisms for Herpes simplex virus type 1 pathogenesis in Alzheimer's disease. Front Aging Neurosci, 2018, 10:48. https://doi.org/10.3389/ fnagi.2018.00048 PMID: 29559905 PMCID: PMC5845560

[154] Urosevic N, Martins RN. Infection and Alzheimer's disease: the APOE epsilon4 connection and lipid metabolism. J Alzheimers Dis, 2008, 13(4):421-435. https://doi.org/10. 3233/jad-2008-13407 PMID: 18487850

[155] van der Steen JT, Lane P, Kowall NW, Knol DL, Volicer L. Antibiotics and mortality in patients with lower respiratory infection and advanced dementia. J Am Med Dir Assoc, 2012, 13(2):156-161. https://doi.org/10.1016/j.jamda.2010. 07.001 PMID: 21450193 PMCID: PMC6290468

[156] Ganguli M, Dodge HH, Shen C, Pandav RS, DeKosky ST. Alzheimer disease and mortality: a 15-year epidemiological study. Arch Neurol, 2005, 62(5):779-784. https://doi.org/ 10.1001/archneur.62.5.779 PMID: 15883266

[157] Verkhratsky A, Olabarria M, Noristani HN, Yeh CY, Rodriguez JJ. Astrocytes in Alzheimer's disease. Neurotherapeutics, 2010, 7(4):399-412. https://doi.org/10.1016/ j.nurt.2010.05.017 PMID: 20880504 PMCID: PMC5084302

[158] Frost GR, Li YM. The role of astrocytes in amyloid production and Alzheimer's disease. Open Biol, 2017, 7(12):170228. https://doi.org/10.1098/rsob.170228 PMID: 29237809 PMCID: PMC5746550

[159] Zaiou M. Multifunctional antimicrobial peptides: therapeutic targets in several human diseases. J Mol Med (Berl), 2007, 85(4):317-329. https://doi.org/10.1007/s00109-006-0143-4 PMID: 17216206

[160] Gosztyla ML, Brothers HM, Robinson SR. Alzheimer's amyloid- $\beta$ is an antimicrobial peptide: a review of the evidence. J Alzheimers Dis, 2018, 62(4):1495-1506. https:// doi.org/10.3233/JAD-171133 PMID: 29504537

[161] Bourgade K, Garneau H, Giroux G, Le Page AY, Bocti C, Dupuis $G$, Frost $E H$, Fülöp T Jr. $\beta$-Amyloid peptides display 
protective activity against the human Alzheimer's diseaseassociated Herpes simplex virus-1. Biogerontology, 2015, 16:85-98. https://doi.org/10.1007/s10522-014-9538-8 PMID: 25376108

[162] White MR, Kandel R, Tripathi S, Condon D, Qi L, Taubenberger J, Hartshorn KL. Alzheimer's associated $\beta$-amyloid protein inhibits influenza $A$ virus and modulates viral interactions with phagocytes. PLoS One, 2014, 9(7):e101364. https://doi.org/10.1371/journal.pone.0101364 PMID: 24988208 PMCID: PMC4079246

[163] Green DA, Masliah E, Vinters HV, Beizai P, Moore DJ, Achim CL. Brain deposition of beta-amyloid is a common pathologic feature in HIV positive patients. AIDS, 2005, 19(4):407-411. https://doi.org/10.1097/01.aids.000016177 $0.06158 .5 c$ PMID: 15750394

[164] Rahman A, Al-Qenaie S, Rao MS, Khan KM, Guillemin GJ. Memantine is protective against cytotoxicity caused by lead and quinolinic acid in cultured rat embryonic hippocampal cells. Chem Res Toxicol, 2019, 32(6):1134-1143. https:// doi.org/10.1021/acs.chemrestox.8b00421 PMID: 30950269

[165] Pellegrini JW, Lipton SA. Delayed administration of memantine prevents $\mathrm{N}$-methyl-D-aspartate receptor-mediated neurotoxicity. Ann Neurol, 1993, 33(4):403-407. https://doi.org/ 10.1002/ana.410330414 PMID: 8098195

[166] Chou CL, Yeh HI. The role of the renin-angiotensin system in amyloid metabolism of Alzheimer's disease. Acta Cardiol Sin, 2014, 30(2):114-118. PMID: 27122777 PMCID: PMC 4805016

[167] Gebre AK, Altaye BM, Atey TM, Tuem KB, Berhe DF. Targeting renin-angiotensin system against Alzheimer's disease. Front Pharmacol, 2018, 9:440. https://doi.org/10. 3389/fphar.2018.00440 PMID: 29760662 PMCID: PMC 5937164

\section{Corresponding authors}

Dragoş Marinescu, Professor, MD, PhD, Doctoral School, University of Medicine and Pharmacy of Craiova, 2 Petru Rareş Street, 200349 Craiova, Dolj County, Romania; Phone +40251-522 458, e-mail: marinescu_psy@yahoo.com Ion Cristian Efrem, Assistant Professor, MD, PhD, Department of Internal Medicine, Faculty of Dental Medicine, University of Medicine and Pharmacy of Craiova, 2 Petru Rareş Street, 200349 Craiova, Dolj County, Romania; Phone +40785-216 697, e-mail: ic_efrem@yahoo.com 